\title{
Host response mechanisms in periodontal diseases
}

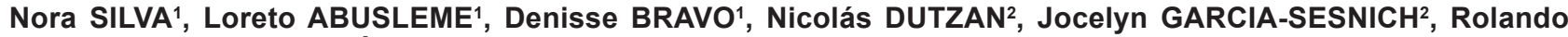 \\ VERNAL ${ }^{2}$, Marcela HERNÁNDEZ ${ }^{3}$, Jorge GAMONAL ${ }^{2}$
}

\footnotetext{
1- Laboratory of Microbiology, Department of Pathology, Faculty of Dentistry, University of Chile, Santiago, Chile.

2- Laboratory of Periodontal Biology, Department of Conservative Dentistry, Faculty of Dentistry, University of Chile, Santiago, Chile.

3- Laboratory of Periodontal Biology, Department of Pathology, Faculty of Dentistry, University of Chile, Santiago, Chile.
}

Corresponding address: Jorge Gamonal - Facultad de Odontología - Universidad de Chile - Avenida Sergio Livingstone 943, Comuna de Independencia Santiago - Chile - Phone: 0056-2-978 1700 - e-mail: jgamonal@odontologia.uchile.cl

Submitted: November 10, 2014 - Modification: January 25, 2015 - Accepted: February 11, 2015

\section{ABSTRACT}

$\mathrm{P}$ eriodontal diseases usually refer to common inflammatory disorders known as gingivitis and periodontitis, which are caused by a pathogenic microbiota in the subgingival biofilm, including Porphyromonas gingivalis, Aggregatibacter actinomycetemcomitans, Tannerella forsythia and Treponema denticola that trigger innate, inflammatory, and adaptive immune responses. These processes result in the destruction of the tissues surrounding and supporting the teeth, and eventually in tissue, bone and finally, tooth loss. The innate immune response constitutes a homeostatic system, which is the first line of defense, and is able to recognize invading microorganisms as non-self, triggering immune responses to eliminate them. In addition to the innate immunity, adaptive immunity cells and characteristic cytokines have been described as important players in the periodontal disease pathogenesis scenario, with a special attention to CD4+ T-cells (T-helper cells). Interestingly, the T cell-mediated adaptive immunity development is highly dependent on innate immunity-associated antigen presenting cells, which after antigen capture undergo into a maturation process and migrate towards the lymph nodes, where they produce distinct patterns of cytokines that will contribute to the subsequent polarization and activation of specific T CD4+ lymphocytes. Skeletal homeostasis depends on a dynamic balance between the activities of the bone-forming osteoblasts (OBLs) and bone-resorbing osteoclasts (OCLS). This balance is tightly controlled by various regulatory systems, such as the endocrine system, and is influenced by the immune system, an osteoimmunological regulation depending on lymphocyte- and macrophage-derived cytokines. All these cytokines and inflammatory mediators are capable of acting alone or in concert, to stimulate periodontal breakdown and collagen destruction via tissue-derived matrix metalloproteinases, a characterization of the progression of periodontitis as a stage that presents a significantly host immune and inflammatory response to the microbial challenge that determine of susceptibility to develop the destructive/progressive periodontitis under the influence of multiple behavioral, environmental and genetic factors.

Keywords: Periodontitis. Periodontal diseases. Progressive periodontitis. Pathogenesis. Osteoimmunology. Metalloproteinases.

\section{I- ETIOLOGY OF PERIODONTAL DISEASE}

Periodontal diseases usually refer to common inflammatory disorders known as gingivitis and periodontitis, which are caused by a pathogenic microbiota in the subgingival biofilm. The bacterial challenge induces the production of cytokines and chemokines by the gingival epithelium, resulting in the expression of adhesion molecules, increased permeability of gingival capillaries and chemotaxis of polimorphonuclear neutrophils through the junctional epithelium and into the gingival sulcus ${ }^{53,173}$. If this process continues, the inflammation extends deep into the tissues and causes loss of supporting connective tissue, alveolar bone and also allows the formation of a periodontal pocket. Those recently described pathologic events constitute and characterize what we know as periodontitis ${ }^{84}$. 
A hallmark of periodontitis is that is caused by complex subgingival microbial communities, which can comprise around 500 bacterial species ${ }^{171}$. The human body contains various and distinctive ecosystems providing a unique environment for colonizing microorganisms. Moreover, the oral cavity presents numerous surfaces for microbial colonization. For instance, the periodontal sulcus/ pocket is partially sheltered from the physical shear forces in the oral cavity and contains hard and non-shedding surfaces of the tooth root, along with the shedding surfaces of gingival mucosa in permanent contact with the gingival crevicular fluid $^{211}$. The epithelial surfaces are continuously replaced; however, several of the most pathogenic bacterial species are able to invade the gingival cells and tissues, remaining viable and evading the action of different immune cells ${ }^{237}$. Therefore, the subgingival environment has distinct ecological determinants, and it can be considered as one of the most interesting oral niches for characterizing the intimate interplay between oral microbial communities and the immune host response.

Usually, a few bacterial species in the subgingival biofilm have been associated with diseased periodontal tissues and identified as putative pathogens. It was concluded that there is strong evidence that Porphyromonas gingivalis ( $P$. gingivalis), Aggregatibacter actinomycetemcomitans (A. actinomycetemcomitans) and Tannerella forsythia ( $T$. forsythia) are periodontal pathogens when their presence is in sufficient numbers and in susceptible hosts ${ }^{31}$.

Although many efforts have been made to characterize the prevalence of the periodontal pathogens described above, there is little consensus due to the varied methodologies used. For that reason, our group investigated the differences in 9 bacterial species of the subgingival microbiota of chronic periodontitis populations in Chile, Spain and Colombia using the same clinical and microbiological methods ${ }^{90}$. In that study, the red complex species $P$. gingivalis and $T$. forsythia, were detected in high frequencies in most of the patients and the actives sites. $P$. gingivalis were the most frequently detected in Chilean patients $(83.8 \%)$ and the less frequent in Colombians (65.9\%), while the frequency of $T$. forsythia was lower in Chile (16.2\%) than in Colombia (39\%) and Spain $(36.1 \%)^{90}$. Additionally, our group reported that active sites in Chileans with chronic periodontitis showed higher mean percentages for $P$. gingivalis of the total anaerobic than inactive sites, and no significant differences were found for T. forsythia ${ }^{204}$. Our findings are in agreement with the ones previously described by López, et al. ${ }^{137}$ (2004), who found a higher prevalence of $P$. gingivalis in Chilean than US subjects, using checkerboard DNA-
DNA hybridization. This study demonstrated that more than $90 \%$ of active sites are colonized by red complex bacteria, but the prevalence of $T$. forsythia was lower than $P$. gingivalis and similar in Chilean and in US subjects ${ }^{137}$ (Figure 1 ).

The high prevalence of $P$. gingivalis and $T$. forsythia in Chileans with chronic periodontitis was in accordance with studies performed in other Latin American populations. Using DNA-based methods, it was reported a high frequency of $P$. gingivalis and $T$. forsythia in Brazilian (68\% and 45\%, respectively) and Mexican population (100\% and $97.4 \%$, respectively) 33, 252 (Figure 1 ). In addition, using microbiological cultures, Botero, et al. ${ }^{21}$ (2007) were able to detect $P$. gingivalis and $T$. forsythia in a high frequency in Colombians patients with chronic periodontitis (75.4\% and $50 \%$, respectively). Together these results indicate that $P$. gingivalis and $T$. forsythia are frequently detected in Latin American population with chronic periodontitis, however, the prevalence of $P$. gingivalis is higher in Chile compared to other Latin American countries (Figure 1).

Regarding $A$. actinomycetemcomitans prevalence in chronic periodontitis, our group reported that this pathogen was detected in a lower proportion than $P$. gingivalis and $T$. forsythia in Chilean population, using microbiological culture ${ }^{54}$ and DNA probes ${ }^{137}$. Also using microbiological cultures, lower proportions and frequency of $A$. actinomycetemcomitans were found in Chilean (19.4\%), Colombian (17.1\%) and Spaniard $(16.7 \%)$ populations. However, the Chilean population presented a higher frequency of detection than US patients ${ }^{137}$ (Figure 1 ). In contrast, in Brazilian ${ }^{35}$ and Mexican ${ }^{256}$ patients with chronic periodontitis, a higher frequency of detection of $A$. actinomycetemcomitans has been reported, using PCR and checkerboard DNA-DNA hybridization, respectively. These findings are worth noting, since it has been demonstrated that the frequency detection of some periodontopathic microorganisms in chronic periodontitis subjects was significantly higher when detected by PCR than in microbiological cultures ${ }^{21}$.

On the other hand, a very high prevalence of $P$. gingivalis was also found in patients with aggressive periodontitis in Chileans ${ }^{55,135,136}$, Brazilians $^{35}$, Mexicans ${ }^{256}$ and Colombians subjects ${ }^{21}$. Interestingly, concerning the microbiological profiles described in periodontitis, some studies have found differences in the periodontal microbiota between chronic and aggressive periodontitis ${ }^{21,35,55,256}$, however, more recent studies have reported only minor differences in the microbiological profiles of both clinical entities ${ }^{186}$.

Using different DNA-based assays and microbiological cultures of periodontal pathogens, it has been reported that some populations with 
aggressive periodontitis have a higher prevalence of $P$. gingivalis compared with the ones with chronic periodontitis (Figure 1). For example, our group reported that Chilean patients with aggressive periodontitis have $86.6 \%-100 \%$ of $P$. gingivalis frequency of isolation, compared with $76.4 \%$ in chronic periodontitis ${ }^{55}$. Also using microbiological cultures, it was reported a frequency of $92.8 \%$ in Colombian subjects with aggressive periodontitis compared with $75.4 \%$ for the ones with chronic

\begin{tabular}{|c|c|c|c|c|c|c|c|c|c|c|}
\hline Author & Number of & Disease type & Method of & \multicolumn{7}{|c|}{ Prevalence of periodontopathic bacteria per individual } \\
\hline $\begin{array}{l}\text { López, } \\
\text { et al. }{ }^{135} \\
\text { (1995) }\end{array}$ & $\begin{array}{c}\mathrm{n}=15 \\
\text { Chileans }\end{array}$ & $\begin{array}{c}\text { Localized Juvenile } \\
\text { Periodontitis (LJP; } \\
\text { n=10), Generalized } \\
\text { Juvenile Periodontitis } \\
\text { (GJP; } n=5 \text { ) }\end{array}$ & $\begin{array}{l}\text { Microbiological } \\
\text { Culture } \\
\text { (7 bacterial } \\
\text { species) }\end{array}$ & $\begin{array}{c}P \text {. gingivalis } \\
\text { A. actinomycetemcomitans }\end{array}$ & $\begin{array}{c}\text { LJP } \\
70.0 \% \\
40.0 \%\end{array}$ & & & \begin{tabular}{|c|} 
GJP \\
$80.0 \%$ \\
$60.0 \%$
\end{tabular} & & \\
\hline $\begin{array}{l}\text { López, } \\
\text { et al. }{ }^{136} \\
(1996)\end{array}$ & $\begin{array}{c}\mathrm{n}=24 \\
\text { Chileans }\end{array}$ & $\begin{array}{l}\text { Localized Juvenile } \\
\text { Periodontitis (LJP; } \\
\text { n=18), Generalized } \\
\text { Juvenile Periodontitis } \\
\text { (GJP; } n=6)\end{array}$ & $\begin{array}{l}\text { DNA probes } \\
\text { (3 bacterial } \\
\text { species) }\end{array}$ & $\begin{array}{c}P \text {. gingivalis } \\
\text { A. actinomycetemcomitans }\end{array}$ & $\begin{array}{c}\text { LJP } \\
94.4 \% \\
38.9 \%\end{array}$ & & & $\begin{array}{l}\text { GJP } \\
0 \% \\
0 \%\end{array}$ & & \\
\hline $\begin{array}{l}\text { Tinoco, } \\
\text { et al. }{ }^{235} \\
(1997)\end{array}$ & $\begin{array}{c}\mathrm{n}=25, \\
\text { Brazilians }\end{array}$ & $\begin{array}{l}\text { Localized Aggressive } \\
\text { periodontitis (LAgP) }\end{array}$ & $\begin{array}{l}\text { Microbiological } \\
\text { Culture } \\
\text { (1 bacterial } \\
\text { species) }\end{array}$ & A. actinomycetemcomitans & $\begin{array}{l}\mathrm{LAgP} \\
76 \%\end{array}$ & & & & & \\
\hline $\begin{array}{l}\text { López }^{134} \\
(2000)\end{array}$ & $\begin{array}{c}\mathrm{n}=60 \\
\text { Chileans }\end{array}$ & $\begin{array}{c}\text { Progressive } \\
\text { Periodontitis (PP) }\end{array}$ & $\begin{array}{l}\text { DNA probe } \\
\text { (3 bacterial } \\
\text { species) }\end{array}$ & $\begin{array}{c}P \text {. gingivalis } \\
\text { A. actinomycetemcomitans }\end{array}$ & $\begin{array}{c}\mathrm{PP} \\
96 \% \\
11.6 \% \\
\end{array}$ & & & & & \\
\hline $\begin{array}{l}\text { López, } \\
\text { et al. }{ }^{137} \\
(2004)\end{array}$ & $\begin{array}{c}\mathrm{n}=26 \\
\text { Chileans }\end{array}$ & $\begin{array}{c}\text { Chronic Periodontitis } \\
\text { (CP) }\end{array}$ & $\begin{array}{l}\text { Checkerboard } \\
\text { DNA-DNA } \\
\text { hybridization } \\
\text { (40 bacterial } \\
\text { species) }\end{array}$ & $\begin{array}{c}\text {. gingivalis } \\
\text { T. forsythia } \\
\text { A. actinomycetemcomitans }\end{array}$ & $\begin{array}{c}\text { CP } \\
>9 \times 10^{5} \\
\text { counts } \\
>6 \times 10^{5} \\
\text { counts } \\
>3 \times 10^{5} \\
\text { counts }\end{array}$ & & & & & \\
\hline $\begin{array}{l}\text { Gajardo, } \\
\text { et al. }{ }^{55} \\
(2005)\end{array}$ & $\begin{array}{c}\mathrm{n}=53 \\
\text { Chileans }\end{array}$ & $\begin{array}{c}\text { Chronic } \\
\text { Periodontitis (CP; } \\
\mathrm{n}=17 \text { ), Localized } \\
\text { (LAgP; } \mathrm{n}=30 \text { ) } \\
\text { and Generalized } \\
\text { Aggressive } \\
\text { Periodontitis (GAgP; } \\
\mathrm{n}=6 \text { ) }\end{array}$ & $\begin{array}{l}\text { Microbiological } \\
\text { Culture } \\
\text { (8 bacterial } \\
\text { species) }\end{array}$ & $\begin{array}{c}P \text {. gingivalis } \\
\text { A. actinomycetemcomitans }\end{array}$ & $\begin{array}{c}\mathrm{CP} \\
76.4 \% \\
35.2 \%\end{array}$ & & $\begin{array}{l}\text { LAgP } \\
86.6 \% \\
16.6 \%\end{array}$ & & & $\begin{array}{l}\text { GAgP } \\
100 \% \\
33.3 \%\end{array}$ \\
\hline $\begin{array}{l}\text { Cortelli, } \\
\text { et al. }{ }^{35} \\
(2005)\end{array}$ & $\begin{array}{c}\mathrm{n}=203 \\
\text { Brazilians }\end{array}$ & $\begin{array}{c}\text { Aggressive } \\
\text { Periodontitis (AgP; } \\
n=25) \\
\text { Chronic Periodontitis } \\
\text { (CP; } n=178)\end{array}$ & $\begin{array}{c}\text { PCR } \\
\text { (5 bacterial } \\
\text { species) }\end{array}$ & $\begin{array}{c}\text { P. gingivalis } \\
\text { T. forsythia } \\
\text { A. actinomycetemcomitans }\end{array}$ & $\begin{array}{c}\mathrm{CP} \\
68.0 \% \\
45.5 \% \\
41.6 \%\end{array}$ & & & $\begin{array}{c}\mathrm{AgP} \\
80.0 \% \\
56.0 \% \\
72.0 \%\end{array}$ & & \\
\hline $\begin{array}{l}\text { Ximenez- } \\
\text { Fyvie, } \\
\text { et al. }{ }^{256} \\
(2006)\end{array}$ & $\begin{array}{c}\mathrm{n}=77 \\
\text { Mexicans }\end{array}$ & \begin{tabular}{|c|} 
Generalized \\
Aggressive \\
Periodontitis (GAgP; \\
$n=19)$ \\
Chronic \\
Periodontitis (CP; \\
$n=39)$ \\
Periodontally Healthy \\
$(H ; n=19)$
\end{tabular} & $\begin{array}{l}\text { Checkerboard } \\
\text { DNA-DNA } \\
\text { hybridization } \\
\text { (40 bacterial } \\
\text { species) }\end{array}$ & $\begin{array}{c}\text { P. gingivalis } \\
\text { T. forsythia } \\
\text { A. actinomycetemcomitans }\end{array}$ & $\begin{array}{c}\mathrm{CP} \\
100 \% \\
97.4 \% \\
89.7 \%\end{array}$ & $\begin{array}{l}\text { GAgP } \\
100 \% \\
94.4 \% \\
94.7 \%\end{array}$ & & & \begin{tabular}{|c|}
$\mathrm{H}$ \\
$89.5 \%$ \\
$89.5 \%$ \\
$73.7 \%$ \\
\end{tabular} & \\
\hline $\begin{array}{l}\text { Botero, } \\
\text { et al. }{ }^{21} \\
(2007)\end{array}$ & $\begin{array}{c}\mathrm{n}=110 \\
\text { Colombians }\end{array}$ & \begin{tabular}{|} 
Chronic Periodontitis \\
(CP; $n=68)$, \\
Aggressive \\
Periodontitis \\
(AgP; $n=12$ ) and \\
Periodontally Healthy \\
$(\mathrm{H} ; \mathrm{n}=30)$
\end{tabular} & $\begin{array}{l}\text { Microbiological } \\
\text { culture, } \\
\text { biochemical } \\
\text { tests and PCR } \\
\text { (11 bacterial } \\
\text { species) }\end{array}$ & $\begin{array}{c}\text { P. gingivalis } \\
\text { T. forsythia } \\
\text { A. actinomycetemcomitans }\end{array}$ & $\begin{array}{c}\mathrm{CP} \\
75.4 \% \\
50.0 \% \\
15.4 \%\end{array}$ & \begin{tabular}{|c|}
$\mathrm{AgP}$ \\
$92.8 \%$ \\
$51.4 \%$ \\
$10.0 \%$
\end{tabular} & & & \begin{tabular}{|c|}
$\mathrm{H}$ \\
$10.0 \%$ \\
$6.7 \%$ \\
$6.7 \%$
\end{tabular} & \\
\hline $\begin{array}{l}\text { Herrera, } \\
\text { et al. } .^{90} \\
(2008)\end{array}$ & $\begin{array}{c}\mathrm{n}=114 \\
\text { Colombians } \\
\text { (co), Chileans } \\
\text { (ch), Spaniards } \\
\text { (sp) }\end{array}$ & $\begin{array}{l}\text { Chronic Periodontitis } \\
\text { (Chileans; } n=37 \text {, } \\
\text { Colombians; } n=41 \text {, } \\
\text { Spaniards; } n=36 \text { ) }\end{array}$ & $\begin{array}{l}\text { Microbiological } \\
\text { culture } \\
\text { ( } 9 \text { bacterial } \\
\text { species) }\end{array}$ & $\begin{array}{c}\text { P.gingivalis } \\
\text { T. forsythia } \\
\text { A. actinomycetemcomitans }\end{array}$ & $\begin{array}{l}\text { CP (ch) } \\
83.4 \% \\
16.2 \% \\
19.4 \%\end{array}$ & $\begin{array}{l}\text { CP (co) } \\
65.9 \% \\
39.0 \% \\
17.1 \%\end{array}$ & & & \begin{tabular}{l|} 
CP (sp) \\
$77.8 \%$ \\
$36.1 \%$ \\
$16.7 \%$
\end{tabular} & \\
\hline $\begin{array}{l}\text { Rescala, } \\
\text { et al. }{ }^{186} \\
(2010)\end{array}$ & $\begin{array}{c}\mathrm{n}=44, \\
\text { Brazilians }\end{array}$ & $\begin{array}{c}\text { Generalized Chronic } \\
\text { periodontitis (GCP; } \\
\text { n=20), Generalized } \\
\text { Aggressive } \\
\text { periodontitis (GAgP; } \\
\text { n=14), Gingivitis (G; } \\
n=10 \text { ) }\end{array}$ & $\begin{array}{l}\text { Checkerboard } \\
\text { DNA-DNA } \\
\text { hybridization } \\
\text { (40 bacterial } \\
\text { species) }\end{array}$ & $\begin{array}{c}\text { P. gingivalis } \\
\text { T. forsythia } \\
\text { A. actinomycetemcomitans }\end{array}$ & $\begin{array}{l}\text { GCP } \\
>6 \times 10^{5} \\
\text { counts } \\
>6 \times 10^{5} \\
\text { counts } \\
<2 \times 10^{5} \\
\text { counts }\end{array}$ & \begin{tabular}{|l|} 
GAgP \\
$>6 \times 10^{5}$ \\
counts \\
$>6 \times 10^{5}$ \\
counts \\
$<2 \times 10^{5}$ \\
counts
\end{tabular} & & & \begin{tabular}{|c|}
$G$ \\
$<2 \times 10^{5}$ \\
counts \\
$<1 \times 10^{5}$ \\
counts \\
$<2 \times 10^{5}$ \\
counts
\end{tabular} & \\
\hline
\end{tabular}

Figure 1- Comparison of the frequency of detection of Porphyromonas gingivalis, Tannerella forsythia and Aggregatibacter actinomycetemcomitans in Latin American subjects with different periodontal diagnosis 
periodontitis ${ }^{21}$. According to these results, using PCR, it has been reported that Brazilian patients with aggressive periodontitis had $80 \%$ of prevalence compared with $68 \%$ for chronic periodontitis patients, whereas similar prevalence was observed for $T$. forsythia in both pathologies ${ }^{35}$. In contrast, studies performed with checkerboard DNA-DNA hybridization method showed a similar amount of $P$. gingivalis and T. forsythia in Mexicans subjects ${ }^{256}$ as well as in Brazilians ${ }^{186}$ (Figure 1).

After red complex bacteria, the prevalence of A. actinomycetemcomitans is the most elevated in Chilean ${ }^{134,136}$ and Brazilian ${ }^{235}$ populations with aggressive periodontitis; however, it is quite different among populations. For example, Chilean subjects had a lower frequency of detection of this microorganism in aggressive (16.6\% in localized aggressive periodontitis and $33.3 \%$ in generalized aggressive periodontitis) than in chronic periodontitis (35.2\%)54. In addition, Botero, et al. ${ }^{21}$ (2007) found in Colombian patients a $10 \%$ of frequency of detection in aggressive and $15.4 \%$ in chronic periodontitis. In contrast, Ximenez-Fyvie, et al. ${ }^{256}$ (2006) describes in Mexican subjects a higher prevalence of $A$. actinomycetemcomitans (94.7\%) in generalized aggressive periodontitis patients.

Regarding the studies described above, some of them have shown differences on the microbial profiles in subjects with the same clinical entities, when comparing populations of different countries. Therefore, the only presence of particular bacteria could not explain by itself the etiology of periodontal diseases. Consequently, many of the current studies are focusing their analysis on the bacterial subspecies of the main periodontopathogens ( $P$. gingivalis, $A$. actinomycetemcomitans and $T$. forsythia), their serotypes and strains with specific genetic characteristics ${ }^{151 .}$

P. gingivalis, a Gram-negative, black pigmented, assacharolytic and strict anaerobic bacteria, has long been considered an important member of the periodontopathic microbiota involved in periodontal disease progression and bone and tissue destruction ${ }^{93}$. A large body of evidence supports that $P$. gingivalis produces an array of potential virulence factors ${ }^{164}$. Some of them are lipopolysaccharide, capsule, hemagglutinins, fimbriae, serB protein and cysteine proteases called "gingipains" $82,93,100,176,177,261$. The pathological actions of gingipains includes aminoacid uptake from host proteins, fimbrial maturation, macrophage CD14 degradation and cleavage of complement component $\mathrm{C} 5^{131}$. Altogether, these effects facilitate a sustained colonization of $P$. gingivalis.

On the other hand, similar to other Gramnegative bacteria, this microorganism can synthesize an extracellular capsule, composed of negatively charged polysaccharides that enable this bacterium to withstand phagocytosis ${ }^{50,198}$. Six different serotypes based on capsular (K) antigens have been described for $P$. gingivalis and designated K1- K6 125,243 . Recently, Vernal, et al. ${ }^{249}$ (2009) has demonstrated that each $P$. gingivalis $\mathrm{K}$ serotype induces a different type of immune response, suggesting a role of the capsule in the activation of dendritic cells. This virulence factor may be an important pathogenic determinant in the initiation, progression, and/or severity of the periodontitis.

In addition, another critical virulence factor is major fimbriae. These are filamentous components on the cell surface, and their subunit protein, fimbrillin (FimA), reportedly acts on bacterial interaction with host tissues by mediating bacterial adhesion and colonization in targeted sites ${ }^{4}$. $P$. gingivalis strains had been classified into six different variants (types I-V and type Ib) based on their different nucleotide sequences. Several studies have been performed to investigate the prevalence and distribution of these fimA genotypes in subjects with different periodontal conditions in different geographical locations ${ }^{147-149,157}$. From those results, it can be inferred that the type II fimA genotypes is the most prevalent in periodontitis patients, while the second most prevalent has been variably found to be type IV, type Ib, or type I, depending on the ethnic population studied. Conversely, type I and type III fimA are more prevalent in nonperiodontitis subjects 5 .

Furthermore, lipopolysaccharide represents a major component of $P$. gingivalis outer membrane and in contrast to most Gram-negative bacteria, lipid A from $P$. gingivalis lipopolysaccharide present heterogeneous molecules that induce a weak agonistic and antagonistic innate immune response ${ }^{42,104}$. These mechanisms are proposed to be essential in disrupting the oral homeostasis and oral health.

Regarding $A$. actinomycetemcomitans, is a Gram-negative bacterium that produces numerous factors that have been well-characterized, including adherence proteins, biofilm polysaccharides, lipopolysaccharide, and toxins ${ }^{51}$. Specifically, 2 protein toxins have been related to periodontal diseases mediated by $A$. actinomycetemcomitans: the cytolethal distending toxin (CDT) 202 and leukotoxin $(\operatorname{Ltx} A)^{116,126}$, which have been implicated in impaired of human lymphocyte function by perturbing cell cycle progression and the lymphocytic and monomyelocytic lineages lysis ${ }^{207}$, respectively. Both proteins are delivered to the host cell by outer membrane vesicles (OMVs) ${ }^{190}$ and participate in immune evasion mechanisms ${ }^{107}$.

Finally, $T$. forsythia is a Gram-negative bacterium strongly associated with the development and/ or progression of periodontal disease. Only a few virulence factors of $T$. forsythia have been 
recognized to be involved in the pathogenesis of periodontitis, which includes sialidase ( $\mathrm{SiaHI})$ and $\mathrm{NanH}$, a cysteine protease with hemolysin activity (PrtH), a trypsin-like protease and an extracellular protein, BspA, mediating the attachment to fibronectin and fibrinogen, an apoptosis-inducing activity, alpha-D-glucosidase and $\mathrm{N}$-acetyl-betaglucosaminidase, a hemagglutinin, components of the bacterial S-layer, and methylglyoxal production ${ }^{81,122,200}$.

Taken together, these antecedents are showing that several virulence factors produced by these periodontal pathogens might be important in the immune response impairment, and permit to these bacteria to exert a significant impact on the oral homeostasis and the development of periodontal diseases.

\section{II- INNATE IMMUNITY IN PERIODONTAL DISEASES}

Periodontal disease is initiated by small subset of endogenous gram-negative periodontal bacteria, including Porphyromonas gingivalis, Aggregatibacter actinomycetemcomitans, Tannerella forsythia and Treponema denticola, which trigger innate, inflammatory, and adaptive immune responses. These processes result in the destruction of the tissues surrounding and supporting the teeth, and eventually result in tissue, bone, and, finally, tooth loss $^{5,113,130 \text {. }}$.

The innate immune response constitutes a homeostatic system, which is the first line of defense and is able to recognize invading microorganisms as non-self, triggering immune responses to eliminate them. The effectors mechanisms of innate immune are improved by adaptive immune involving an efficient loop for microbial clearance, where triggering of proper innate mechanisms ensures an effective adaptive immune response, which potentiate these innate effectors functions against periodontopathic bacteria. The primary response to pathogens in the innate immune system is triggered by Pattern Recognition Receptors (PRRs) that bind Pathogen-Associated Molecular Patterns (PAMPs), found in a broad type of organisms. These receptor types include toll-like receptors, nucleotide-binding oligomerization domain (NOD) proteins, cluster of differentiation 14 (CD14), complement receptor-3, lectins and scavenger receptors ${ }^{3,9}$.

Latin-American research about innate immune response and periodontitis is mainly focused on the toll-like receptor and neutrophils. Such research is developed in Brazil, Chile and Mexico $56,64,131,187,189$ (Figure 2).

\section{Toll-like receptors}

Among the most important families of pathogen- associated molecular patterns are the tolllike receptors (TLRs), which recognize, with selectivity, a large number of varied and complex pathogen-associated molecular patterns. Toll-like receptors are evolutionarily conserved proteins that also have a highly conserved intracellular TIR domain involved in protein-protein interaction and signaling activation. The extracellular domain, with Leucine-rich repeats (LRRs), is related to ligand recognition. Leucine-rich repeats motifs vary among toll-like receptors, although how they can discriminate among different pathogenassociated molecular patterns still remains unclear $^{3}$. Among the 10 human toll-like receptors identified so far, toll-like receptor- 2 and toll-like receptor-4 are the most defined members. Toll-like receptor-2 is mostly involved in the recognition of a variety of different bacterial cell components, such as peptidoglycan and lipoproteins. Toll-like receptor-4 has been shown to specifically recognize lipopolysaccharide of Gram-negative bacteria and acts in cooperation with several protein components, such as lipopolysaccharide-binding protein and CD143,9,112,152. Research has established that toll-like receptors are expressed in periodontal tissues ${ }^{152,222}$. Since the gingiva is constantly exposed to microbes present in plaque biofilm, toll-like receptors signaling plays an important role in the innate immune response and maintenance of periodontal health. However, over-production of pro-inflammatory cytokines due to chronic stimulation of toll-like receptors, they may lead to tissue destruction ${ }^{13,254}$.

Several studies have been made in Latin America about toll-like receptors and periodontitis ${ }^{64,131,189}$ and all of them, like in almost all dental scientific literature, are related to toll-like receptors 2, tolllike receptors 4 (expressed at the cell surface), tolllike receptors 3 or toll-like receptors 9 (expressed at intracellular compartments). Rojo-Botello, et al. ${ }^{189}$ (2012) showed, using confocal microscope, that toll-like receptors 2, 3, 4 and 9 are expressed in human gingival tissue, and that the expressions were higher in all periodontal patient than in healthy individuals. The authors also demonstrated that the expression of these receptors is positively regulated with the severity of periodontal disease. These data are confirming and extending previous evidence showing the expression of diverse tolllike receptors in various types of cells in the healthy and diseased human gingival tissue, and supports the possible involvement of the toll-like receptors system in the pathogenesis of periodontal disease ${ }^{12,152,222,240}$. Furthermore, the study of RojoBotello shows, for the first time, that the expression of some toll-like receptors (toll-like receptors 2, 4 and 9) is significantly increased in gingival tissue from patients with periodontal disease associated 


\begin{tabular}{|c|c|c|c|}
\hline Author (year) & Methods & Main findings & Origin \\
\hline Gamonal, et al..$^{56}(2003)$ & $\begin{array}{l}\text { Evaluation of apoptosis by } \\
\text { TUNEL technique in ex vivo } \\
\text { culture of gingival biopses in } \\
\text { presence of GM-CSF. }\end{array}$ & $\begin{array}{l}\text { GM-CSF diminishes the } \\
\text { neuthophil apoptosis } \\
\text { by reduction of Bax } \\
\text { expression, suggesting a } \\
\text { novel mechanism by which } \\
\text { neutrophils accumulate } \\
\text { in chronic periodontitis } \\
\text { patients. }\end{array}$ & Chile-Spain \\
\hline Restaíno, et al. ${ }^{187}$ (2007) & $\begin{array}{c}\text { Neutrophils from } 23 \text { chronic } \\
\text { periodontitis and } 30 \\
\text { healthy subjects stimulated } \\
\text { with } P \text {. gingivalis and } A \text {. } \\
\text { actinomicetemcomitans }\end{array}$ & $\begin{array}{l}\text { Neutrophils from chronic } \\
\text { periodontitis subjects are } \\
\text { more reactive, suggested } \\
\text { by their higher response } \\
\text { toward periodontal pathogen } \\
\text { stimulation. }\end{array}$ & Chile \\
\hline Gelani, et al. ${ }^{64}$ (2009) & $\begin{array}{l}\text { A. actinomicetemcomitans- } \\
\text { induced periodontal disease } \\
\text { in TLR2-/- mice }\end{array}$ & $\begin{array}{l}\text { TLR2 is involved in A. } \\
\text { actinomicetemcomitans } \\
\text { recognition and has an } \\
\text { essential role in controlling } \\
\text { A. actinomicetemcomitans } \\
\text { infection. }\end{array}$ & Brazil \\
\hline Lima, et al. ${ }^{131}(2010)$ & $\begin{array}{l}\text { A. actinomicetemcomitans- } \\
\text { induced periodontal disease } \\
\text { in TLR4-/- mice }\end{array}$ & $\begin{array}{l}\text { TLR4 has a role } \\
\text { in controlling } \mathrm{A} \text {. } \\
\text { actinomicetemcomitans } \\
\text { infection. }\end{array}$ & Brazil \\
\hline Rojo-Botello, et al. ${ }^{189}$ (2012) & $\begin{array}{c}\text { Expression of TLRs 2, 3, } \\
4 \text { and } 9 \text { in gingival tissues } \\
\text { from healthy individuals and } \\
\text { from periodontal patients } \\
\text { with or without type } 2 \\
\text { diabetes }\end{array}$ & $\begin{array}{l}\text { The expression of TLRs } 2 \text {, } \\
3,4 \text { and } 9 \text { in gingival tissue } \\
\text { is higher in individuals with } \\
\text { diabetes, and is positively } \\
\text { regulated with the severity of } \\
\text { periodontal disease. }\end{array}$ & Mexico \\
\hline
\end{tabular}

GM-CF: Granulocyte monocyte-colony stimulating factor

TRL:Toll-like receptor

TUNEL: TdT-mediated dUTP-biotin nick end labeling

Figure 2- Evidence regarding innate immune response in periodontitis conducted by Latin-American groups

with type 2 diabetes, with regard to tissues from subjects without diabetes and with or without periodontitis ${ }^{189}$. These findings are consistent with the notion sustaining a correlation between toll-like receptors expression with disease severity, or with the degree of inflammation.

Using a model of experimental periodontitis, a Brazilian group has studied the mechanisms that modulate the outcome of $A$. actinomycetemcomitansinduced periodontal disease in toll-like receptors $2^{-1-64}$ and toll-like receptors $4^{-/-131}$ mice. Toll-like receptors $2^{-/-}$mice developed more severe periodontitis after infection, characterized by significantly higher bone loss. Also an intraperitoneal $A$. actinomycetemcomitans infection model was used to characterize the role of toll-like receptors 2 in the recruitment of macrophages and neutrophils. The initiation of the inflammatory response in toll-like receptors $2^{-1-}$ mice was reduced compared to wild type (WT) controls. Specifically, they observed that the influx of neutrophils and macrophages into the peritoneal cavities was significantly decreased, and the levels of interleukin-1 $\beta$, tumor necrosis factor-a, CXCL2, and CCL5 were significantly lower in tolllike receptors $2^{-1-}$ mice ${ }^{64}$. These data highlight the involvement of toll-like receptors 2 in recognizing A. actinomycetemcomitans and its essential role in controlling $A$. actinomycetemcomitans infection. On the other hand toll-like receptors $4^{-/}$mice orally infected with $A$. actinomycetemcomitans developed less severe periodontitis, when compared with wild type (WT) control mice, characterized by a significantly lower bone loss accompanied by a reduced inflammatory cell migration and 
inflammatory cytokine production (interleukin$1 \beta$ and tumor necrosis factor- $a$ ) in periodontal tissues. Moreover, this absence of toll-like receptors 4 activation leads to impaired myeloperoxidese activity in the periodontum and possibly facilitates systemic bacteria dissemination and proliferation ${ }^{135}$. Regarding $P$. gingivalis, an interaction of fimbriae with TLR2 has also been shown to induce cross talk of TLR2 with the coreceptors CR5, CXCL4, and CR3, resulting in distinct responses ${ }^{82}$. The plasticity and diversity in downstream signaling when TLR2 is activated is further underscored by the observation that $P$. gingivalis live cells induce a different pattern of TLR2-dependent cytokines than that induced by FimA or LPS preparations alone in mouse peritoneal macrophages ${ }^{265}$. It is likely that different TLR2-activating ligands vary in their abilities to engage TLR2 and specific coreceptors. In terms of responses, TLR2 engagement has been shown to trigger production of both proinflammatory and anti-inflammatory cytokines.

The bacterial composition of plaque remains relatively stable despite regular exposure to minor environmental perturbations. The changes that affect the homeostasis leading to shifts for example in the frequent exposure of plaque to low $\mathrm{pH}$; an increase flow of gingival crevicular fluid; and as microflora shifts from being mainly Gram-positive to being comprised of increased levels of obligately anaerobic, asaccharolytic Gram-negative organisms and the rate of acid production following sugar intake could be reduced by fluoride, have been incorporated into a new hypothesis: the ecological plaque hypothesis, to explain the relationship between the plaque microflora and the host in health and disease, and to identify new strategies for disease prevention ${ }^{145}$.

The recent advancements in the periodontal research field are consistent with a new model of pathogenesis, according to which periodontitis is initiated by a synergistic and dysbiotic microbial community rather than by a select bacterial complex, that is, polymicrobial synergy and dysbiosis model (PSD model) ${ }^{79,80}$.

\section{Polymorphonuclear neutrophils}

Polymorphonuclear neutrophils are one of the first-responders of inflammatory cells to migrate toward the site of periodontal inflammation, following chemoattractants such as interleukin-8 secreted by oral epithelial cells, connective fibroblast and immune cells. In addition, polymorphonuclear neutrophils are recruited to the site of injury within minutes following injury, and are the hallmark of acute inflammation ${ }^{39}$.

Though the polymorphonuclear neutrophils are essentially protective cells, alterations in polymorphonuclear neutrophil function result in an acute, severe and generalized clinical phenotype of periodontitis in humans ${ }^{42}$. These alterations can involve different functions such as adhesion capabilities, chemotaxis response and phagocytic function and, by default, the specific timing of polymorphonuclear neutrophils-based periodontal immune response. Their cytoplasmic granules contain several enzymes that, on release, degrade the structural elements of tissue cells and extracellular matrix. Polymorphonuclear neutrophils are short-lived cells, and also upon interaction with pathogens and its toxins, they die in great numbers at acute inflammatory periodontal sites. Therefore, the accumulation and massive death of polymorphonuclear neutrophils are among major causes for tissue breakdown in progressive periodontitis. $P$. gingivalis associated periodontitis has been related to a disruption on $\mathrm{E}$-selectin endothelial cells expression and interleukin- 8 expression from gingival epithelial cells that could alter significantly the polymorphonuclear neutrophils transit to the inflammation site ${ }^{39,42}$. Regarding the response of polymorphonuclear neutrophils, our group studied peripheral blood neutrophils in periodontitis-affected patients, and in healthy controls towards stimulation to $P$. gingivalis and $A$. actinomycetemcomitans extracts ${ }^{187}$. Neutrophil response, followed by matrix metalloproteinase- 9 and interleukin- 8 secretion, was assayed by zymography and enzyme-linked immunosorbent assay, respectively, on both whole blood and purified neutrophils. In addition to periodontal pathogen extracts, known stimulating agents were tested, such as Escherichia coli lipopolysaccharide, phytohemagglutinin, and zymosan A. Polymorphonuclear neutrophil response expressed as a secretion ratio, under stimulated and non-stimulated conditions in purified neutrophils from patients. The tests showed that the matrix metalloproteinase- 9 exhibited a significantly higher secretion ratio with lipopolysaccharide and $P$. gingivalis, whereas interleukin- 8 showed a larger increase in secretion ratio in the presence of $P$. gingivalis, $A$. actinomycetemcomitans, lipopolysaccharide, and zymosan A. Our study concludes that peripheral neutrophils of periodontitisaffected patients are more reactive than in controls as suggested by their significantly higher response toward periodontal pathogen extracts and other stimulating agents. This hyper-reactivity may be secondary to the inflammatory reaction occurring in the gingival tissue during periodontal disease ${ }^{187}$. Finally, another study from our group, showed that granulocyte monocyte-colony stimulating factor (GM-CSF) present in the gingival crevicular fluid, could delay polymorphonuclear neutrophil apoptosis in chronic periodontitis ${ }^{56}$. To probe that, we utilized cultures of human gingival biopsies obtained 
from periodontitis subjects. When the sample was embedded in complete medium containing granulocyte monocyte-colony stimulating factor, the total number of TUNEL-positive cells was reduced, therefore showing its delaying effect on the apoptotic process. The localized accumulation of functional polymorphonuclear neutrophils at sites of inflammation is pivotal in the host defense against infection, and the orderly elimination of these cells is equally important in the resolution of the inflammatory response ${ }^{56}$.

\section{III- INVOLVEMENT OF T-CELL SUBSETS, CYTOKINES AND ORAL VIRUSES IN PERIODONTAL DISEASES PATHOGENESIS}

In addition to the innate immunity, adaptive immunity cells and characteristic cytokines have been described as important players in the periodontal disease pathogenesis scenario, with a special attention to $\mathrm{CD}^{+}{ }^{+} \mathrm{T}$-cells (T-helper cells). Interestingly, $\mathrm{T}$ cell-mediated adaptive immunity development is highly dependent on innate immunity-associated antigen presenting cells, which after antigen capture undergo into a maturation process and migrate towards the lymph nodes, where they produce distinct patterns of cytokines that will contribute to the subsequent polarization and activation of specific T CD4+ lymphocyte ${ }^{38}$.

$\mathrm{CD}^{+}{ }^{+}$T-cells were subdivided initially into two subsets, designated T-helper 1 and T-helper 2, on the basis of their pattern of cytokine production ${ }^{155}$. As a general rule, T-helper 1 cytokines have been associated with infectious inflammatory bone destruction, while its classic antagonists T-helper 2 cytokines are described to minimize bone loss $30,73,180,184$. Nevertheless, the discovery of new T-helper subsets with prominent roles in the modulation of host responses determined the re-examination of T-helper 1/T-helper 2 dichotomy paradigm in chronic inflammatory diseases, including periodontal diseases $21,73,103,205,252$. Th17 cells emerged as a remarkable $T$ subset, with inflammatory properties involved in a series of infectious, autoimmune and osteolytic processes $44,106,224,226$.

On the other hand, regulatory $T$ cells (Tregs) comprise a FOXp3-dependent CD $4+C D 25^{+}$ T-helper subpopulation with suppressive effects on inflammatory osteolysis, thought to be mediated by cytokines such transforming growth factor- $\beta$, interleukin-10 and the CLTA4 ${ }^{18,106}$. Other regulatory $T$ cell subsets, namely T-helper 3 and Tr1, are characterized by the specific production of transforming growth factor- $\beta$ or interleukin-10, respectively ${ }^{16,17,103}$.

Also, additional T-helper subsets, such as
T-helper 9 and T-helper 22 cells, are described to play important roles in the modulation of inflammatory immune responses, interacting with the previously mentioned T-helper subpopulations ${ }^{103,154,252}$.

Therefore, we must consider that there are at least four types of T-helper cells, T-helper 1, T-helper 2, T-helper 17, and T-regulatory cells, which collectively play an important role in orchestrating adaptive immune responses to various infectious agents, and also a great influence on the inflammatory and autoimmune diseases outcome. Upon TCR-mediated cell activation, and under a critical influence of cytokines that generate specific patterns of signaling and activate definite transcription factors, naïve $\mathrm{CD}^{+}{ }^{+} \mathrm{T}$ cells can differentiate into characteristic polarized subsets. Specific subsets of cytokines are involved in differentiation of each lineage: interleukin-12/interferon-y for T-helper 1, interleukin-4/interleukin-2/interleukin-7 for T-helper 2, transforming growth factor- $\beta$ / interleukin-6/interleukin-21/interleukin-23 for T-helper 17, and transforming growth factor- $\beta$ / interleukin-2 for T-regulatory cells. The major effect of such polarizing cytokines is the generation of specific transcription factors involved in T-helper cell differentiation: T-bet controls T-helper 1 fate, GATA3 is involved in T-helper 2 generation, RORyt for T-helper 17, and Foxp3 for T-regulatory cells.

Once differentiated, the polarized T-helper subsets express a signature pattern of chemokine receptors expression that determines the selective migration of $\mathrm{CD}^{+}{ }^{+} \mathrm{T}$ helper subsets to the response foci, in which these cells will produce distinct and characteristic cytokines ${ }^{20,108,155}$. Indeed, the transcription factors involved in T-helper cell differentiation directly bind to the effector cytokine genes (Ifng, Il4/II13, Il17a/Il17f; for T-helper 1, T-helper 2 and T-helper 17 cells respectively) at promoters and regulatory elements, resulting the prototypical production of cytokines that defines the T-helper subsets 266,267 . In this context, we describe in the sequence the major T-helper subsets and their potential role in the pathogenesis of periodontal diseases.

\section{T-helper 1}

T-helper 1 cells are primarily involved in the cellmediated immunity, and are generated under the influence of interleukin-12/interferon- $\gamma$ signaling that leads to the activation of the transcription factor T-bet. Interferon- $\gamma$, the signature cytokine of T-helper 1-type responses, is associated with the production of inflammatory cytokines and chemokines and with phagocyte activation 7,155,194,199. A controversial role for interferon-y in bone lytic lesions has been described, since in vitro data clearly demonstrated that interferon- $\gamma$ induces rapid 
degradation of the RANK adapter protein TRAF6 by the ubiquitin-proteasome system, resulting in the inhibition of the RANKL-signaling and its subsequent osteoclastogenic events ${ }^{227}$. These results can be interpreted in support of the hypothesis that T-helper 1 cells are associated with the stable lesions while T-helper 2 cells are associated with disease progression ${ }^{66}$. However, Garlet lab group ${ }^{57,58}$ demonstrated in vivo that the pro-inflammatory effect of interferon- $\gamma$ mediates the upregulation of the levels of tumor necrosis factor-a and interleukin$1 \beta$, which in turn can upregulate RANKL, being the in vivo outcome opposite to the in vitro scenario.

Accordingly, as previously demonstrated by Gamonal and Garlet groups, interferon-y is present at high levels in human and experimental periodontal lesions, being associated with progressive lesions or higher severity periodontal diseases forms ${ }^{46,61,94}$. Human and experimental data suggests that interferon-y can contribute to periodontitis onset and progression by distinct mechanisms. With special interest in T-helper 1 cells, our group demonstrates in a series of studies that interferon- $y$ stimulates osteoclast formation and bone loss in vivo via antigen-driven $T$ cell activation or through the chemoattraction of RANKL+ cells ${ }^{58,63,183}$. In fact, T-helper 1 cells (characterized as CD3+CCR5+CXCR3+ cells) are an important source of RANKL throughout experimental periodontitis ${ }^{183}$. Complementarily, interferon- $y$ can contribute to the migration of CD4/80+ cells, whose phenotype demonstrate monocyte/macrophage-like phenotype that can be interpreted as a potential osteoclast precursor's subpopulation. Finally, interferon-y seems to play an active role in the control of periodontal infection, possibly mediated by macrophages and neutrophils activation ${ }^{146,199}$ clearly evidenced by the severe impairment of protective immunity to $A$. actinomycetemcomitans infection, as demonstrated by the higher bacterial load in periodontium, increased acute phase response, and bacterial dissemination followed by death of interferon-y $\mathrm{KO}$ mice $^{56}$. The immune protection mediated by interferon- $y$ characteristically involves leukocyte recruitment and its subsequent activation at inflammatory foci ${ }^{199}$.

\section{T-helper 2}

T-helper 2 cells commitment and action is primarily dependent of interleukin-4, the prototypical T-helper 2 cytokine, and of the transcription factor GATA37,152,191. Interleukin-4 presents marked suppressive and anti-inflammatory properties mediated by its capacity to inhibit the transcription of pro-inflammatory cytokines and interferon- $y$, then suppressing the polarization

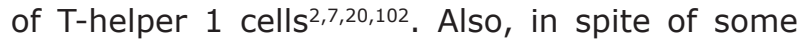
controversies, interleukin-4 can present anabolic properties in distinct tissues, characterized by the ability to inhibit the production of tissue degrading factors such as matrix metalloproteinases (and other proteases) and the major osteoclastogenic factor RANKL, and concomitantly induce the upregulation of its respective inhibitors TIMPs and osteoprotegerin ${ }^{98,192,194}$. Therefore, interleukin-4 could contribute to the attenuation of both soft and mineralized tissue destruction, which could reinforce its potential protective nature in periodontitis pathogenesis ${ }^{67}$.

Indeed, the concentration of interleukin-4 in gingival crevicular fluid was demonstrated to decrease from periodontal health to disease, suggesting that this cytokine could mediate the remission or improvement of periodontal lesions ${ }^{179}$. Experimental data support the protective role of T-helper 2 cells, since T-helper 2-biased immune response in mice resulted in minimal lesions after $P$. gingivalis challenge $\mathrm{e}^{220}$, and the adoptive transfer T-helper 2 cells attenuates the severity of periodontal diseases ${ }^{47}$. In this context, it is important to remember that interleukin-4 cab induces the production of cytokines with similar or complementary suppressive properties, such as interleukin-10 105,172. Interestingly, interleukin-10 was considered initially one of the T-helper 2-signature cytokines along interleukin-4, but more recent studies have been associating this cytokine more closely to T-regulatory cells. It is also important to mention that recent studies have been identified an interesting plasticity among T-helper subsets, which may also account for some controversies in previous studies.

However, early studies demonstrated that B cells outnumber T cells in periodontal lesions, which in the view of the association of T-helper 2 responses with $B$ cell function and humoral immunity development, results in the hypothesis that a T-helper 2 lesion was involved in the progression of chronic periodontitis ${ }^{65}$. Recent evidences, demonstrating that $B$ cells can be a RANKL source, and that the majority of B cells in periodontal lesions are RANKL $+{ }^{110}$ are interpreted along with the T-helper 2 lesion hypothesis. While in this context the T-helper 2-B cell axis is considered detrimental, it is important to consider that the humoral immunity axis involving T-helper 2 and $B$ cells is also thought to contribute to the host protection against periodontal pathogens ${ }^{75,168,169,200}$.

\section{T-helper 17}

T-helper 17 cell lineage is characterized as an interleukin-17-producing CD4 T cell subset, which undergoes its polarization due to a complex cytokine signaling that can involve, transforming growth factor- $\beta$ /interleukin-6/interleukin-21/interleukin-23 and resulting in the activation of the transcription factor ROR-g. In this process, transforming growth 
factor- $\beta$ and interleukin- 6 signaling together cooperate to drive T-helper 17 commitment, while the cytokine interleukin-23 amplifies and stabilizes the T-helper 17 phenotype in chronic inflammatory reactions. Interestingly, T-helper 17 cells develop through cytokine signals distinct from, and antagonized by, products of the T-helper 1 and T-helper 2 lineages $7,44,194$. Once differentiated, RORY can bind to multiple sites in the Il17a/II17f locus, including the promoters of these cytokines, leading to the characteristic interleukin-17 production, which in turn leads to the induction of many proinflammatory factors such as tumor necrosis factor, interleukin-6, and interleukin- $1 \beta$. In fact, these innate immunity cytokines have been associated with periodontitis, since the upregulation of such mediators expression/production by interleukin-17 clearly points to a destruction of such cytokines in periodontitis context. Accordingly, Gamonal groups presented the initial evidences that T-helper 17 cytokines are produced in periodontal lesions and are supposed to contribute to disease progression, which was confirmed latter by Garlet group and others ${ }^{12,24,162,163,223,247}$. Besides the classical phagocyte activating cytokines, recent evidences demonstrate that the T-helper 17/interleukin-17 axis, by itself or along with pro-inflammatory and T-helper 1 cytokines, mobilizes macrophages and neutrophils ${ }^{204,262}$, which could also contribute to exacerbate host responses in periodontal tissues. In accordance with this hypothesis, interleukin-17 was also recently described to increase toll-like receptors responsiveness in human gingival epithelial cells ${ }^{13}$, suggesting that this cytokine can play an active role in potentiating innate immunity mechanisms in periodontal environment. In addition to the upregulation of pro-inflammatory cytokines production, interleukin-17 was described as an inducer of RANKL production ${ }^{120,195,197}$. However, experimental studies in rodents demonstrate that the interleukin-17 deficient mice may present increased or decreased bone lesions in response to periodontal pathogens challenge, being the exact role of interleukin-17 in periodontitis still unclear $^{166,262}$.

\section{T-regulatory cells}

Regulatory $T$ cells were initially described as $\mathrm{CD} 4{ }^{+} \mathrm{CD} 25^{+} \mathrm{T}$ cells that specifically regulate the activation, proliferation, and effector function of activated conventional $\mathrm{T}$ cells, determining the outcome of several immunological settings ranging from infectious diseases to immunopathology and autoimmunity $7,15,194,203$. T-regulatory cells characteristically express as phenotypic markers the transcription factor forkhead box P3 (FOXp3), CD103, the glucocorticoid-inducible tumor necrosis factor receptor (GITR), the inhibitory molecule cytotoxic T-lymphocyte-nassociated molecule 4 (CTLA-4) and cell surface transforming growth factor- $\beta 1$, among other surface molecules ${ }^{203}$. However, recent studies demonstrate that FOXP3+ T cells are not a uniform population, but phenotypically and functionally diverse populations. Currently, there are two accepted major types of FOXP3+ T-regulatory cells: endogenous or natural Treg (nTreg), a stable subset derived from the thymus and thought to control autoreactivity, and adaptive or induced T-regulatory cells (aTreg or iTreg), a less stable subpopulation supposed to regulate responses upon antigenic exposure in the periphery ${ }^{15,150,191,193}$. Interestingly, T-regulatory cells from noninflamed peripheral tissues are considered to be in a resting state with little suppressor activity, but under certain inflammatory conditions, these cells are stimulated and undergo rapid reprogramming to acquire helper/effector functions. Foxp 3 is the master regulator for both iT-regulatory cells and nT-regulatory cells, and its stimulation through TCR and transforming growth factor- $\beta R$ signaling is essential to drive iT-regulatory cells development. Along with other transcription factors, such as Runx, Foxp3 positively regulates T-regulatory cells-specific gene expression and negatively regulates genes not expressed in Tregs ${ }^{15,150,191}$.

Immunohistological, flow-cytometry and molecular analysis of periodontal tissues characterized the presence and identity of T-regulatory cells by the expression of its phenotypic markers FOXp3, CTLA-4, interleukin-10, GITR, CD103 and $\mathrm{CD} 45 \mathrm{RO}^{25,158}$. Despite the controversies regarding T-regulatory cells subtypes and phenotypes, and the lack of definitive markers, according to the current knowledge it is possible to suggest that iT-regulatory cells would be the cells found in periodontal tissues. While the effector mechanisms of T-regulatory cells action can greatly vary, inhibitory factors such as CTLA-4, interleukin-10 and transforming growth factor- $\beta$ are supposed to mediate suppressive activity in peripheral tissues. Accordingly, these three factors are also supposed to attenuate periodontal diseases progression, restraining inflammation and osteoclastogenesis locally 25,60,62,109,127,165,221. Indeed, Gamonal group demonstrated that, in active periodontal lesions, T-regulatory cells-related cytokines levels are negatively correlated with RANKL levels, reinforcing its protective role against tissue destruction $45,46,221$. In accordance with such hypothesis, Garlet group was the first to establish a cause/effect association between T-regulatory cells and periodontitis severity by means of T-regulatory cells function ablation, in an experimental periodontitis model, where the migration of $\mathrm{CD}^{+}{ }^{+} \mathrm{FOXp3} 3^{+}$cells to periodontal tissues after experimental infection is associated 
with a decline in the disease progression rate, and its inhibition resulted in increased alveolar bone loss and inflammatory cell migration ${ }^{59}$. In addition to the attenuation of tissue destruction, T-regulatory cells-associated cytokines such as interleukin-10 and transforming growth factor- $\beta$ are associated with tissue repair in different models ${ }^{29}$.

\section{Additional T-helper subsets}

While T-helper 1, T-helper 2, T-helper 17 and T-regulatory cells are the most recognized and studied T-helper subsets, recent studies suggest the existence of other CD4 lymphocytes subtypes with distinguished immunoregulatory properties. T-helper 9 cells characteristically produce interleukin-9, initially designated as a T-helper 2 cytokine that exerts pro- or anti-inflammatory activities by modulating T-regulatory cells and/or T-helper 17 cells development and function 49,128,129,161. Additionally, the recently identified T-helper 22 cells produces interleukin-22, which can exerts pro-inflammatory effects by a synergistic action with classic pro-inflammatory mediators such as tumor necrosis factor-a of interleukin-1749,252. Preliminary data from Garlet group demonstrate that both interleukin-9 and interleukin-22 are overexpressed in diseased periodontal tissues, reinforcing the complexity of cytokine networks in the inflamed periodontal environment. Here, we simultaneously investigated the expression of pro- and anti-inflammatory, T-helper 1, T-helper 2, T-helper 9, T-helper 17, T-helper 22 and T-regulatory cells cytokines/markers, and the major osteoclastogenesis regulators RANKL and osteoprotegerin, in human chronic periapical granulomas and their possible correlations with lesions activity pattern ${ }^{147}$ in order to obtain a more complete picture of the immunoregulatory scenario in periapical lesions, which ultimately can contribute to the development and to the improvement of the diagnosis and treatment of these pathologies.

\section{The T helper immunoregulatory network}

Despite the reports regarding the expression of prototypical T-helper markers in diseased periodontal tissues, the related hypothesis regarding their role in the pathogenesis of periodontal diseases are often conflicting. In fact, since the production/expression of such factors is usually investigated individually or in small clusters, it does not allow the complete immunoregulatory scenario determination, where the potential synergic or antagonist action of cytokines should be considered. When interpreting in vivo data, the putative function of cytokines must be estimated in the view of a complex milieu, with presence of several other cytokines, which can modulate or be modulated by them in multiple ways until the establishment of an overall outcome. In addition, since the presence of specific periodontopathogens is able to interfere with cytokine milieu, the in vivo scenario with multiple bacterial species turns this network even more complex (Figure $3)$. Interestingly, the simultaneous presence of T-helper 1 and T-helper 2 was previously reported in periodontal lesions, but the interferon-g and interleukin-4 levels of these cytokines were described to be inversely correlated in accordance with the mutual inhibitory activity of these $T$ cell subsets $^{62}$. More recently, studies demonstrate that periodontal lesions simultaneously express high levels of both interleukin-17 and interferon-g, suggesting a possible cooperative detrimental role for these cytokines ${ }^{46,223}$. Conversely, in other models, T-helper 1 and T-helper 17 mediators seem to be independently associated to the progression

\section{Cytokines \& Periodontal Disease}

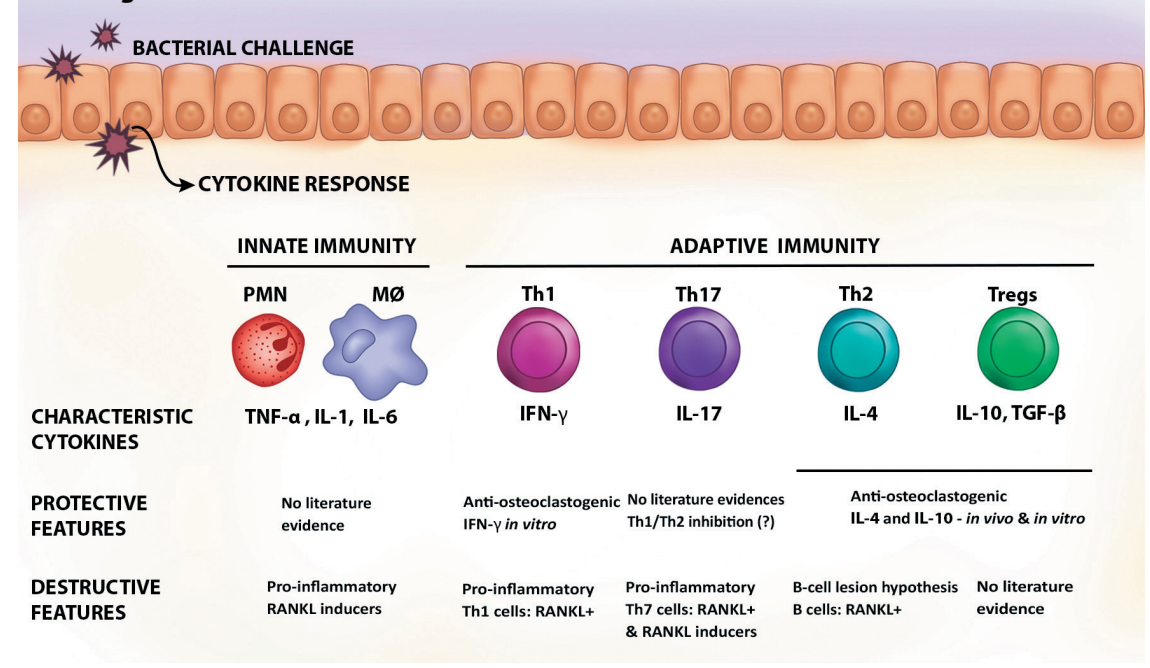

Figure 3- Cytokines and periodontal disease 
of inflammatory bone lesions, suggesting that distinct pathways could result in a similar bone loss outcome $26,236,244$. The possible interactions among T-helper subsets would also involve potentially protective mechanisms, since a T-helper 2/T-regulatory cells crosstalk mediated by transforming growth factor- $\beta$ and interleukin- 4 may drive the polarization of T-helper 9 cells $^{103}$, described to mediate immunosuppressive actions along interleukin-4 and interleukin-10 producing cells 229,257 .

\section{Oral viruses in pathogenesis of periodontal disease}

Periodontitis is considered to be a process that involves a multifactorial interaction among microbial, host and environmental modulating factors ${ }^{84}$. It is accepted that periodontitis is associated with specific bacterial species and polymicrobial colonization of the teeth surfaces ${ }^{6}$, however, the amount of bacterial plaque per se does not completely explain the clinical and pathological features of periodontitis ${ }^{32}$. Periodontal diseases are inflammatory processes characterized by dense accumulation of immune cells, including polymorphonuclear neutrophils, $\mathrm{T}$ and $\mathrm{B}$ lymphocytes, plasma cells, mast cells, monocytes and macrophages ${ }^{25}$. The $T$ cells play an important role in the immune response, regulating the polyclonal activation of the $B$ cells and plasma cells in the periodontitis-affected sites. The interaction between host immune system and periodontopathogens is relevant to the pathogenesis of periodontitis ${ }^{53}$.

Our knowledge of viral infections has increased significantly in the past couple of decades. Herpesviruses may cause illness by mechanisms that are direct, indirect or immune-response linked, and illnesses range from subclinical or mild disease to encephalitis, pneumonia and other potentially lethal infections, and even to lymphoma, sarcoma and carcinoma. In the oral cavity, herpesviruses are involved in acute gingival infections, destructive periodontal disease, apical periodontitis, ulcerations of mucosa, odontogenic cyst, giant cell granuloma, autoimmune disease and various types of neoplasm ${ }^{33}$. Contreras, et al. $^{33}$ (1999) suggested that the presence of herpesviruses in the periodontal sites could play a role on the pathogenesis of human periodontitis. Herpesviruses are ubiquitous and after primary infection can persist latently in the host in several types of cells, including cells of the immune system. The cytomegalovirus (CMV) is the most-studied member of the betaherpesviruses in periodontal sites $^{33}$. Recently, the other two betaherpesviruses, known as human herpesvirus 6 (HHV-6) and human herpesvirus 7 (HHV-7), have been investigated because these viruses are frequently detected in saliva208,209.

Inflammatory cells harboring herpesviruses present at sites of periodontal inflammation could contribute to the development and course of periodontitis ${ }^{32}$. Cytomegalovirus can induce direct cytopathic effects on fibroblasts, keratinocytes, endothelial cells and inflammatory cells, including polymorphonuclear leukocytes, T lymphocytes and macrophages, and also possibly affect bone cells ${ }^{210}$.

In periodontitis patients, $\mathrm{T}$ cells are activated, and specific lymphocyte responses are driven by the nature of the initial antigenic stimuli. This process is supported by a complex cascade of events involving cytokines, chemokines and other inflammatory mediators, which could be altered due to cytomegalovirus infection ${ }^{209}$. Proinflammatory and anti-inflammatory balances controlled by different subsets of lymphocytes are thought to be crucial in the pathogenesis of periodontitis ${ }^{53}$.

The expression of different cellular antigens can be dramatically altered in Beta herpesvirus-infected tissues, in which the viral infection can induce CD4 up regulation and $\mathrm{CD} 3$ down modulation in the $\mathrm{T}$ cells. Human herpesvirus 6 can severely affect the physiology of secondary lymphoid organs through direct infection of $\mathrm{T}$ lymphocytes and modulation of key membrane receptors and chemokines ${ }^{74}$.

Local immunomodulatory effects caused by herpesviral infection could facilitate bacterial proliferation and virulence, or induce the release of cytokines and chemokines from inflammatory and connective tissue cells ${ }^{214}$. In addition, viruses and bacteria could act in synergy to produce pathology 210 .

Herpesviral infections in the periodontium can act as cofactors of periodontal pathogenesis, modulating the activity of inflammatory cells. The release of different types of cytokines and $B$ Iymphocyte activation orchestrated by $T$ lymphocytes has been shown to be an important process in chronic periodontitis. In addition, T-regs cells may be involved in local immune response in periodontitis ${ }^{25}$.

In conclusion, a herpesvirus-bacterial pathogen model has been proposed, in which viral infections facilitate bacterial overgrowth and virulence. Moreover, the immunosuppressive effects of certain herpesviruses can also perpetuate the inflammatory reaction in the connective tissue facilitating periodontal destruction. Human viruses could play a role in human periodontitis by modulation of immune response.

\section{IV- OSTEO-IMMUNOLOG Y PERIODONTAL DISEASES}

Nowadays, it has been clearly demonstrated that increases in RANKL mRNA and protein levels 
in periodontal tissues stimulate the differentiation of monocyte-macrophage precursor cells into osteoclasts, and the maturation and survival of the osteoclast, leading to alveolar bone loss $37,54,91$, $108,132,156,244,248$. In this context, during inflammatory response characteristic of periodontitis, proinflammatory cytokines associated with T-helper 1 and T-helper 17 cell phenotypes, such as interleukin-1 $\beta$, interleukin-6, interleukin-17, interferon- $\gamma$, and tumor necrosis factor-a, can stimulate periodontal osteoblasts to express membrane-bound RANKL1,54,72,140,153. In addition to osteoblasts, RANKL is expressed by a number of other cell types, mainly T-helper 17 lymphocytes $^{108}$ (Figure 4).

Skeletal homeostasis depends on a dynamic balance between the activities of the boneforming osteoblasts (OBLs) and bone-resorbing osteoclasts (OCLs) ${ }^{247}$. This balance is tightly controlled by various regulatory systems, such as the endocrine system, and is influenced by the immune system, an osteoimmunological regulation depending on lymphocyte- and macrophagederived cytokines $188,197,225,251$. An unbalance in favor of bone-resorbing osteoclasts leads to pathological bone resorption, as it has been observed in rheumatoid arthritis, osteoporosis, Paget's disease, bone tumors, and periodontitis ${ }^{188,251}$.

During the 1970's, the first observation pointing towards immune cells influencing the boneresorbing osteoclasts activity was made. Indeed, a factor (OCL-activating factor or OAF) that stimulated bone resorption was detected in the supernatant from cultured human peripheral monocytes stimulated with phytohemagglutinin ${ }^{96}$. Purification of this activity led to the identification of interleukin$1 \beta^{41}$. Nowadays, numerous cytokines have been demonstrated to stimulate bone resorption, including tumor necrosis factor-a, interleukin$1 \alpha$, interleukin-1 $\beta$, interleukin-6, interleukin-11, interleukin-15, and interleukin-17, whereas others such as interleukin-4, interleukin-5, interleukin-10, interleukin-13, interleukin-18, and transforming growth factor- $\beta 1$ inhibited bone resorption 225,251 . In this context, functional characterization of three novel members of the tumor necrosis factorligand and receptor superfamily, the receptor activator of nuclear factor-KB (RANK), its ligand (RANK-ligand or RANKL) and the soluble decoy receptor of RANKL named osteoprotegerin, have contributed significantly to the establishment of osteoimmunology, where these molecular mediators participate as key modulators of physiological and pathological bone resorption $224,234,250$. RANKL exerts its biological effects directly through binding to RANK, inducing OCL differentiation, maturation and activation ${ }^{124}$. Osteoprotegerin inhibits the osteoclastogenesis and induces osteopetrosis when over-expressed in transgenic mice ${ }^{205}$. RANKL has been associated with diverse osteodestructive pathologies, including rheumatoid arthritis, bone tumors, osteoporosis, Paget's bone disease, osteolytic lesions of the facial skeleton, odontogenic lesions and periodontitis $28,37,90,96,97,117,132,231,245,246$.

The identification of RANKL as the $T$ cell cytokine TRANCE (tumor necrosis factor-related activation-induced cytokine) allowed envisaging the possibility that $\mathrm{CD}_{4}{ }^{+} \mathrm{T}$ cells may have the capacity to induce $O C L$ differentiation and activation by directly acting on OCL precursors and on mature OCLs through synthesis of RANKL during osteodestructive diseases ${ }^{117,230,260}$. Furthermore, many well-known osteotropic factors, including tumor necrosis factor- $a$, interleukin- $1 \beta$ and interleukin-6, exert their osteoclastogenic activity by inducing RANL expression on OBLs and $\mathrm{CD}^{+}{ }^{+} \mathrm{T}_{\text {cells }}{ }^{22}$. Th2

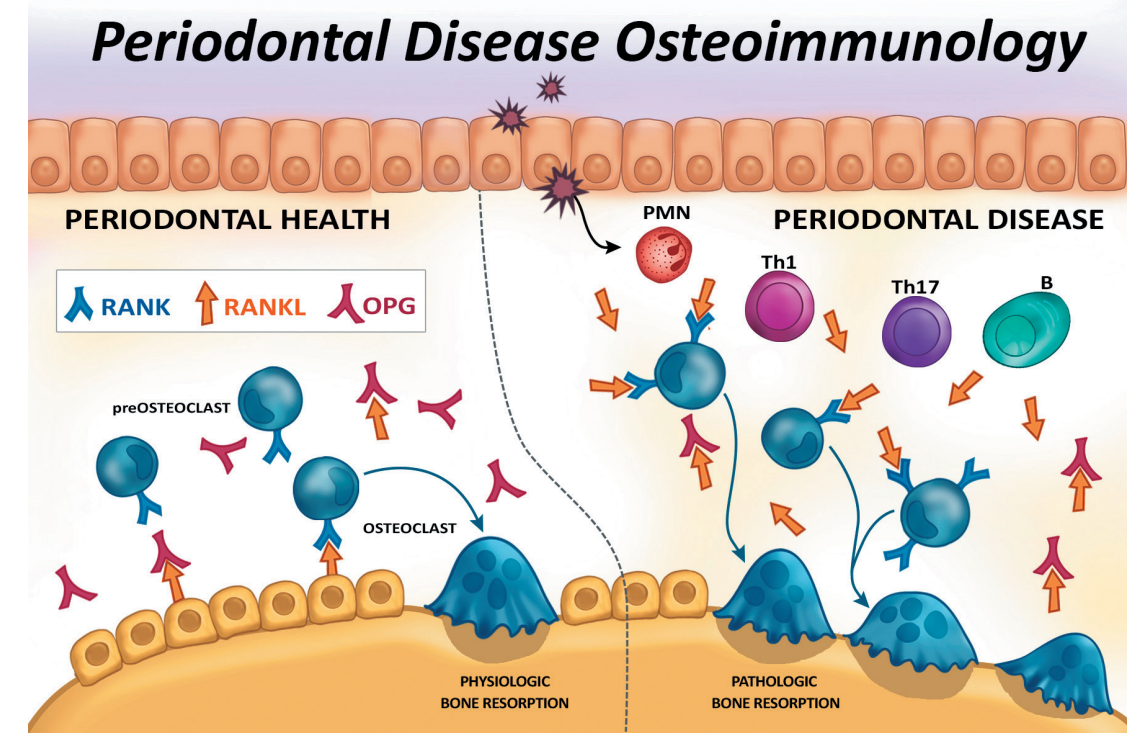

Figure 4- Periodontal disease osteoimmunology 
cells inhibit osteoclastogenesis by acting on the precursor cells, mainly through interleukin-4 and interleukin-10 secretion ${ }^{95,239}$. In contrast, T-helper 17 cells stimulated by interleukin-23 promote osteoclastogenesis mostly through production of interleukin-17 and RANKL ${ }^{196}$. Furthermore, interleukin-17 facilitates local inflammation by recruiting and activating immune cells, which leads to an abundance of inflammatory cytokines such as interleukin- $1 \beta$ and tumor necrosis factor- $a$ that enhance the RANKL expression on OBLs and Th17 cells 27,43

T-helper 17 cells represent a large proportion of the inflammatory cells invading the synovial tissues during rheumatoid arthritis ${ }^{27}$. High levels of interleukin-17A have been detected in the synovial fluid, and interleukin-17-producing cells have been detected within the T cell-rich areas in patients with rheumatoid arthritis ${ }^{138,264}$. Furthermore, interleukin$17 \mathrm{~A}$ is able to promote cartilage destruction and bone erosion in experimental rheumatoid arthritis ${ }^{138}$. Increased levels of interleukin-17 were detected in gingival crevicular fluid and in biopsy samples from periodontal lesions, both at the mRNA and protein levels, in patients with chronic periodontitis, and these increased levels have been associated to $\mathrm{CD}^{+}{ }^{+} \mathrm{T}$ cells $\mathrm{s}^{223,247}$. Furthermore, RANKL and RANK were synthesized within periodontal lesions in which interleukin-17 was produced by activated gingival $T_{\text {cells }}{ }^{247}$. Taken together, these data establish that T-helper 17 cells represent the osteoclastogenic T-helper subset on $\mathrm{CD}^{+} \mathrm{T}$ lymphocytes, inducing osteoclastogenesis and bone resorption through synthesizing interleukin-17 and RANKL (Figure 5).

Our findings have demonstrated that total amount of RANKL detected in gingival crevicular fluid of patients undergoing periodontitis progression was higher in active periodontal lesions than in inactive lesions, proposing this pro-resorptive factor as a marker of active alveolar bone resorption associated with T-helper cell activity 245,246 . This finding was corroborated by Silva, et al. ${ }^{204}$ (2008), whom performed a longitudinal following of 56 patients affected by moderate to severe chronic periodontitis until determination of progression, detecting higher RANKL and interleukin-1 $\beta$ levels, and matrix metalloproteinase-13 activity, in active sites compared with inactive sites.

When the role of T-helper 17 and $T$ regulatory cells phenotypes was analyzed during progressive periodontitis, it was established that interleukin-17 and RANKL were over-regulated, and interleukin-10 and transforming growth factor- $\beta 1$ were downregulated in active periodontal lesions compared with inactive lesions activity ${ }^{45}$. In fact, the overexpression of transcription factor orphan nuclear receptor C2 (RORC2), the master-switch gene controlling the T-helper 17 differentiation, was associated with active periodontal lesions during progressive periodontitis ${ }^{45}$.

In the same study, analysis of the associations between different genes yielded significant positive correlations between RORC2 and RANKL, and between RORC2 and interleukin-17. However, Foxp3, interleukin-10, transforming growth factor- $\beta 1$, and CTLA-4 did not show a positive correlation, speculating that Foxp $3^{+}$T-cells that do not bear regulatory functions may have a role in periodontal progressive destruction, in view of the down-regulation of interleukin-10 and transforming growth factor- $\beta 1^{45}$.

In response to periodontopathogens that have been strongly associated with periodontitis progression, for instance $P$. gingivalis and $A$. actinomycetemcomitans, RANKL expression has been reported to increase in $\mathrm{CD} 4^{+} \mathrm{T}$ lymphocytes infiltrating periodontally affected tissues ${ }^{258}$. In this context, on $\mathrm{T}$ lymphocytes activated with autologous dendritic cells primed with different $P$. gingivalis capsular $(\mathrm{K})$ serotypes and A. actinomycetemcomitans $\mathrm{O}$-polysaccharide serotypes, at different multiplicity of infections, the expression and secretion levels for RANKL were determined. The obtained data showed an increase in RANKL mRNA expression on $\mathrm{T}$ cells activated with $P$. gingivalis $\mathrm{K} 1$ or $\mathrm{K} 2$ serotypes and A. actinomycetemcomitans b serotype, compared with the other serotypes, and these levels correlate

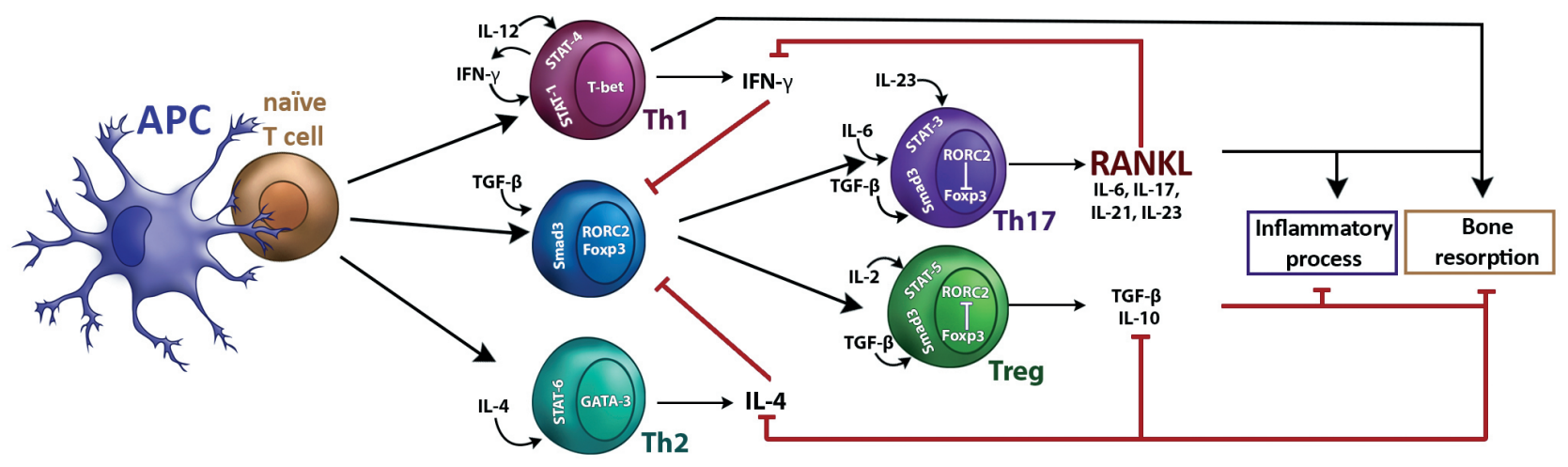

Figure 5- Osteoclastogenesis and bone resorption induction through synthesizing interleukin-17 and RANKL 
with the levels of secreted RANKL present in the supernatant of the cell cultures (unpublished data). These data suggested that activation of $T$ cells with dendritic cells stimulated with either $\mathrm{K} 1$ or K2 serotypes ( $P$. gingivalis) or b serotypes ( $A$. actinomycetemcomitans) induced a T-helper 17 phenotype in $\mathrm{CD}^{+} \mathrm{T}$ cells, and allowed to speculate a link between these serotypes with alveolar bone destruction and teeth loosening, one of the hallmarks of periodontitis.

Diverse studies have analyzed the concentrations of RANKL and osteoprotegerin in gingival crevicular fluid of periodontitis patients and healthy subjects $^{45,204,245-247}$. In general, they show great variation from study to study, but the ratio of RANKL/osteoprotegerin has a consistent tendency to increase from periodontal health to periodontitis, and to decrease following periodontal treatment. The increased RANKL/OPG ratio may serve as a biomarker that denotes the occurrence of periodontitis, but may not necessarily predict ongoing disease activity ${ }^{14}$.

\section{V- THE ROLES OF MATRIX METALLOPROTEINASES IN PERIODONTAL TISSUE BREAKDOWN}

The interaction between periodontal inflammation and persistent bacterial infection up-regulates the expression and activity of neutral proteinases, particularly of the matrix metalloproteinase family, which contributes to the progressive breakdown of periodontal supporting tissue ${ }^{216}$. Matrix metalloproteinases represent a family of human zinc-dependent endopeptidases that are involved in a wide variety of physiological and pathological processes, such as skeletal growth and remodeling, wound healing, cancer and inflammatory diseases. Matrix metalloproteinases are able to degrade basement membrane and extracellular matrix components, and therefore they have been classically viewed as effectors of extracellular matrix hydrolysis. However, matrix metalloproteinases have also regulatory properties, modulating enzyme, chemokine and cytokine activities (referred as bioactive substrates) among others, as well as releasing bioactive molecules from extracellular matrix store through limited proteolysis ${ }^{167,197}$.

Up to now, 24 matrix metalloproteinases have been identified in humans that closely share protein sequence and domain structure, and they are classically grouped according to their structural properties and substrate specificity in collagenases, gelatinases, stromelysins, matrilysins and membrane type matrix metalloproteinases ${ }^{52}$. The basic structure of matrix metalloproteinases is composed of an auto-inhibitory prodomain that maintains enzymatic latency, the catalytic domain and the C-terminal haemopexin-like domain, often involved in the recognition and positioning of matrix metalloproteinase substrates. Matrix metalloproteinase activity is subjected to a complex regulation where the main steps involve gene expression, proenzyme activation and inhibition by endogenous inhibitors, such as tissue inhibitors of matrix metalloproteinases (TIMPs) ${ }^{52,197}$. As a result from matrix metalloproteinase regulation, all human matrix metalloproteinases are known to exist in multiple forms in periodontal diseases, such as latent proforms, active forms, fragmented species, complexed species and cell-bound forms. Overall, the pathophysiological significance of increased matrix metalloproteinase expression and/or levels in periodontitis will rely ultimately on endogenous matrix metalloproteinase activity, resulting from the interactions between their inhibitors and activating factors. Consequently, matrix metalloproteinase activity accounts for the rate of matrix turnover or destruction, and the modulation of the immune response in a more direct fashion ${ }^{23,214}$.

Because collagen I is the main component of the extracellular matrix of soft and hard periodontal tissues, matrix metalloproteinases with collagendegrading properties such as collagenases (matrix metalloproteinase-1, -8, -13 and -14) and gelatinases (matrix metalloproteinases -2 and -9) play a pivotal role in the loss of periodontal support ${ }^{213}$. Collagenases are capable to process native collagen without unwinding the triple helical assembly of the molecule, generating $3 / 4$ $1 / 4$ fragments, whereas gelatinases have been defined according to their affinity for denatured collagen ${ }^{197}$. Accordingly, collagenolytic matrix metalloproteinases have widely been demonstrated in inflamed periodontal tissues and in oral fluids by different analytic methods ${ }^{216-218}$.

Matrix metalloproteinase-8 (collagenase-2) is produced by a wide range of resident and inflammatory cells, but its main source is the neutrophils. Matrix metalloproteinase- 8 represents the major collagenase in gingival tissue and gingival crevicular fluid, accounting for about $80 \%$ of collagenases in gingival crevicular fluid, followed by matrix metalloproteinase-13 $(\sim 18 \%)$, while matrix metalloproteinase- 1 is seldom detected ${ }^{69}$. Despite matrix metalloproteinase- 8 be widely associated with periodontal collagen destruction, increasing evidence is emerging regarding its role over bioactive substrates during periodontal diseases and wound healing. Matrix metalloproteinase-13, also known as collagenase-3, is expressed in hypertrophic chondrocytes and osteoblasts during human fetal development. There is little or no expression of matrix metalloproteinase-13 in normal tissues, showing a very restricted distribution pattern ${ }^{197}$. 
Matrix metalloproteinase-13 upregulation has been involved in periodontitis progression, particularly in bone loss, and its regulatory role is currently under research ${ }^{87,89,99}$. On the other hand, matrix metalloproteinase-1, also known as collagenase- 1 , is produced by several periodontal resident cell-types and is considered as central in the physiological remodeling of extracellular matrix and wound healing ${ }^{197,216}$. Among gelatinases, matrix metalloproteinase- 9 is the main gelatinase in oral fluids ${ }^{139}$. Matrix metalloproteinase- 9 is physiologically expressed by a limited variety of cell types, mainly immune cells, and is highly inducible under periodontal inflammation, whereas matrix metalloproteinase- 2 is less inducible and has primarily a pro-homeostatic role 177,201 .

It has been postulated that heritable differences in the production of cytokines can influence the resistance or susceptibility to periodontitis, as well as disease outcome ${ }^{62}$. Matrix metalloproteinases can be released and/or activated during periodontal inflammation by proinflammatory cytokines, like tumor necrosis factor-a, interleukin-1 $\beta$, reactive oxygen species, and proteases derived from the subgingival biofilm and the host ${ }^{121}$. Accordingly, higher mRNA expression levels of matrix metalloproteinase/TIMP ratios for matrix metalloproteinase- $1,-2$ and -9 , as well as RANKL/ osteoprotegerin ratio, have been reported in gingival tissue from chronic and aggressive periodontitis patients compared with healthy gingival ${ }^{62}$. Furthermore, comparison between gingival tissue from aggressive periodontitis and chronic periodontitis showed higher expression of the regulatory cytokines interleukin-10 and interleukin-4, and reduced Th1- type cytokine interferon (IF)- $y$ expression in the later. The authors suggested that different cytokine patterns might modify the balance of matrix metalloproteinases/ TIMPs and RANKL/osteoprotegerin, resulting in more or less severe periodontal support loss.

Similarly, experimentally-induced periodontitis in mice models by $A$. actinomycetencomitans infection in strains selected for maximal and minimal inflammatory reactions has demonstrated a more severe disease phenotype in the former group. Inflammatory profile was composed of higher interleukin-1 $\beta$, tumor necrosis factor-a, RANKL/ osteoprotegerin ratio and matrix metalloproteinase/ TIMP ratio, particularly of matrix metalloproteinase- 13 and matrix metalloproteinase- $2^{238}$. Similarly, matrix metalloproteinase-13 mRNA expression levels increase concomitantly with the severity of inflammation in two different models of experimentally-induced periodontitis, ligature placement and lipopolysaccharide injections, but the later showed more sustained inflammation. However, the authors found a total lack of correspondence between mRNA transcription and matrix metalloproteinase protein levels ${ }^{8}$, supporting that pro-inflammatory mediators up-regulate matrix metalloproteinase expression in periodontal diseases, but matrix metalloproteinase protein levels and specially matrix metalloproteinase activity needs further assessment.

Several common single nucleotide polymorphisms (SNPs) have been identified in matrix metalloproteinase genes; however, their association with disease susceptibility or phenotype is rather controversial. An example is the matrix metalloproteinase-1 -1607 1G/2G variant ${ }^{9,10,174,241}$. A more recent analysis in a Brazilian population concluded that the $2 \mathrm{G}$ allele associated with higher matrix metalloproteinase-1 levels only in healthy subjects, whereas in periodontitis patients, the antigenic challenge overcame the genetic predisposition ${ }^{185}$. Similar controversial findings have been reported for the matrix metalloproteinase- 9 $\mathrm{T}$ variant at position -1562 in Czech, Turkish, Colombian and Brazilian populations $76,92,101,138,219$. In the case of matrix metalloproteinase-13 and matrix metalloproteinase-8, fewer studies are available; no differences in matrix metalloproteinase-13$77 \mathrm{~A} / \mathrm{G}$ and $-11 \mathrm{~A} / 12 \mathrm{~A}$ polymorphic sites have been found for periodontitis patients ${ }^{175}$. However, a recent study revealed that even if no single matrix metalloproteinase- 8 SNP is associated with periodontitis, the haplotype $T(-799) / C(+17)$ is associated with clinical manifestations of chronic periodontitis in a Czech population ${ }^{102}$.

A vast array of human studies has addressed the association between matrix metalloproteinases and periodontitis at the protein level, showing that matrix metalloproteinase-8 levels parallel the severity of periodontal inflammation and disease. Elevated matrix metalloproteinase- 8 levels in gingival crevicular fluid, saliva and oral rinse differentiate periodontitis from gingivitis and healthy sites $^{142,145}$. Furthermore, matrix metalloproteinase- 8 levels can differentiate periodontitis subjects with strong inflammatory burden from patients with lower levels of inflammation in oral rinse and gingival crevicular fluid ${ }^{128,182}$. Noteworthy, risk factors for periodontal disease, such as tobacco smoking and type 2 diabetes, have shown to influence matrix metalloproteinase- 8 levels in gingival crevicular fluid and saliva from periodontitis subjects ${ }^{81,83,142}$. Tobacco seems to down-regulate matrix metalloproteinase-8 levels; however, the sites with progressive periodontitis show similar matrix metalloproteinase- 8 concentrations, irrespective of the smoking status ${ }^{140}$. Conversely, type-2 diabetes elevates collagenase levels ${ }^{36}$, nevertheless, periodontal treatment has shown to improve clinical parameters and decrease matrix metalloproteinase- 8 levels to a similar extent as 
non-diabetics ${ }^{34}$

Our research group has shown that increased matrix metalloproteinase- 8 levels have been identified in its catalytically active form in gingival crevicular fluid from progressive periodontitis subjects. Among matrix metalloproteinase- 8 isotypes, the neutrophil type predominates over the mesenchymal type in progressive periodontitis. Active forms of polymorphonuclear neutrophils and mesenchymal matrix metalloproteinase- 8 types and their respective activation ratios tended to increase in untreated active sites when compared to inactive sites, defined by the tolerance method, although it was not significant. Conversely, matrix metalloproteinase- 8 proforms and total matrix metalloproteinase- 8 tended to decrease in active sites $^{86}$. In line with these findings, we previously assessed collagenase and gelatinase activities by a functional activity assay, demonstrating increased matrix metalloproteinase activity in gingival crevicular fluid from periodontitis sites $>4 \mathrm{~mm}$ compared to shallower pockets/ sulci ${ }^{178}$. Additionally, we found that non-surgical conventional periodontal treatment has proved to reduce matrix metalloproteinase- 8 and matrix metalloproteinase- 9 levels and activity in accordance with the improvement of clinical parameters, whereas non-responsive sites associate with sustained matrix metalloproteinase- 8 high concentrations $86,178,206,215$. In line with these findings, other research groups have proved that adjunctive low-dose doxycycline (LDD) can also reduce collagenase levels ${ }^{182}$.

Elevated total matrix metalloproteinase-13 levels, as well as proenzyme ( $60 \mathrm{kDa})$ and its active forms ( 45-50 kDa), have been reported in chronic periodontitis versus healthy sites in gingival crevicular fluid in association with periodontal clinical parameters $99,111,232$ and collagen loss ${ }^{48,69}$. Results from our laboratory undergone in chronic periodontitis progression addressed by the tolerance method have demonstrated that matrix metalloproteinase-13 levels were similar among active and inactive sites. However, the former sites had higher matrix metalloproteinase-13 activity, as well as higher bone collagen fragment carboxy-terminal telopeptide of type I collagen (ICTP), and a trend for reduced levels of its inhibitor TIMP-1 ${ }^{87,89}$. Based on these data, pathologically excessive matrix metalloproteinase-13 levels might associate with periodontitis development or severity, whereas the occurrence of disease activity might be better attributed to the unbalance between matrix metalloproteinase-13 and its inhibitor, resulting in increased enzyme activity. The use of matrix metalloproteinase-13 to reflect alveolar bone loss, the hallmark of periodontitis progression, has been proposed ${ }^{68,111}$. These findings suggest that active sites display higher collagen breakdown and bone catabolism in association with matrix metalloproteinase-13 activity. In summary, excessive matrix metalloproteinase-8, matrix metalloproteinase-13 and matrix metalloproteinase- 9 levels and/or activities have been associated with collagen breakdown and periodontal inflammation.

Although the activation mechanisms of matrix metalloproteinases in vivo are still unclear and specific for the affected tissue and disease type, it is conceivable that they might play a major role during periodontal destruction, based on preliminary evidence. Non-proteolytic activation of pro-matrix metalloproteinase- 8 can be directly induced by $\mathrm{MPO}$-derived $\mathrm{HOCl}$ in vitro, which is likely to represent the most direct activating mechanism for triggered neutrophils. MPO can also inactivate pathogenic microbes by generating reactive oxygen species, as well as inactivating TIMPs $^{253}$. Interestingly, we found a significant strong positive correlation between MPO, total matrix metalloproteinase- 8 levels and matrix metalloproteinase- 8 active forms from neutrophils and mesenchymal cells in both active and inactive sites from progressive periodontitis subjects ${ }^{89}$. A positive correlation has also been reported between MPO, total matrix metalloproteinase- 9 and active matrix metalloproteinase- 9 in periodontitis subjects in an analogue manner as for matrix metalloproteinase-8, suggesting a common activation mechanism ${ }^{144}$. Conversely, the later study did not find any association between MPO and matrix metalloproteinase-8, which might eventually be explained regarding the different recognition properties of anti-matrix metalloproteinase- 8 antibodies. It has been widely demonstrated that antibodies applied in the immunoassays for the detection of matrix metalloproteinases and their regulators affect the measurement outcomes $77,128,213,214$. Additionally, our study showed that periodontally treated active sites, where matrix metalloproteinase- 8 remained at high levels, also demonstrated a persistence of MPO/matrix metalloproteinase- 8 association ${ }^{89}$. Based on these findings, active sites might have persistently high matrix metalloproteinase- 8 levels and activation via the oxidative pathway. These findings might reflect the need for further treatment and follow-up.

Besides the importance of a direct collagenolytic role of these matrix metalloproteinases in periodontal tissue breakdown, evidence of a relevant matrix metalloproteinase regulatory role in periodontitis is emerging. In vitro studies demonstrate the existence of an activation cascade between matrix metalloproteinases $-14,-13$ and matrix metalloproteinase-952,114,115. We recently reported matrix metalloproteinase- 13 to enhance pro-matrix 
metalloproteinase- 9 activation rate, which was further prevented by the administration of a matrix metalloproteinase-13 specific synthetic inhibitor in gingival tissue from periodontitis patients ${ }^{81}$. Higher matrix metalloproteinase-14 levels have also been found in gingival tissue from periodontitis subjects compared to controls ${ }^{168}$, and we reported soluble forms of matrix metalloproteinase-14 in periodontitis gingival crevicular fluid 86,232 along with a positive correlation between active matrix metalloproteinase-14 and active matrix metalloproteinase-1387. These results suggest that collagenolytic matrix metalloproteinases -13 , -9 and -14 can potentiate their activities through proteolytic activation during periodontal disease, generating amplifying loops.

Several lines of research based on mouse models provide increasing evidence of the regulatory properties of matrix metalloproteinases. Recently, our group reported that $P$. gingivalisinduced experimental periodontitis in matrix metalloproteinase- 8 null mouse displayed a more severe disease phenotype and reduced levels of mouse lipopolysaccharide-induced CXC chemokine (LIX/CXCL5), the most potent polymorphonuclear neutrophil chemoattractant in mice than their wild type counterparts ${ }^{85,122,123}$. Furthermore, LIX/CXCL5 was immunolocalized to the sulcular epithelium, at the oral-periodontal interface. From our results, it was suggested that physiologic matrix metalloproteinase- 8 levels would be required for periodontal tissue homeostasis, whereas a complete lack of matrix metalloproteinase- 8 might result in a more severe disease phenotype, resulting from a reduced protective polymorphonuclear neutrophil response. Accordingly, LIX/CXCL5 levels have also shown to diminish, as well as polymorphonuclear neutrophil impairment has previously been demonstrated in other matrix metalloproteinase- 8 null mouse models ${ }^{78,159,233,242}$. Nevertheless, direct evidence from functional studies is needed to confirm this proposal. On the other hand, the regulatory effect of matrix metalloproteinase- 8 has further been sustained by other authors that showed reduced levels of transforming growth factor- $\beta 1$ in matrix metalloproteinase-8/- mice in association with polymorphonuclear neutrophil impaired infiltration and wound healing ${ }^{78}$. In an analogous manner to matrix metalloproteinase-8, matrix metalloproteinase- 9 activity has shown to decrease regulate transforming growth factor- $\beta 1$ protein levels in breast cancer cells exposed to tamoxifen ${ }^{11,160}$, whereas recent evidence supports that matrix metalloproteinase-13 might modify soluble protein levels from RANKL/osteoprotegerin axis and consequent bone resorptive activity ${ }^{159}$.

Overall, immunoassays targeting matrix metalloproteinase-8, matrix metalloproteinase-9 and matrix metalloproteinase-13 in oral fluids have a huge potential to differentiate healthy, gingivitis and periodontitis sites or subjects, and treatment response as a complement to classical diagnostic methods $86,142,143,145,213,214$. We have recently assessed the gingival crevicular fluid levels of matrix metalloproteinase- 8 with two different chair-side (dentoAnalyzer by dentognostics $\mathrm{GmbH}$ and matrix metalloproteinase- 8 specific chairside dip-stick test) and two laboratory methods (immunofluorometric assay IFMA, and commercial ELISA) ${ }^{213}$. Both IFMA and dentoAnalyzer devices detected matrix metalloproteinase- 8 levels with similar reliability. It was concluded that repeatedly elevated matrix metalloproteinase- 8 levels indicate the sites at risk of periodontal attachment loss, and that testing of matrix metalloproteinase- 8 in gingival crevicular fluid might provide a valuable side-diagnostic tool, particularly to identify patients at risk for periodontitis recurrence ${ }^{145,213}$.

\section{VI- H O S T - P A T H O G E N INTERACTIONS IN PROGRESSIVE PERIODONTITIS}

Characterization of progressive lesions in chronic periodontitis patients has been controversial over time, and mechanisms involved in protection versus destruction of the host's periodontium are still not fully understood. Evidence indicates that periodontal disease has dynamic states of exacerbation and remission, which can be described in terms of patterns of disease progression and regression $70,71,133,212$. Loss of attachment recorded by sequential probing assessments is thought to reflect the cumulative effect of such repeated episodes and represents the most commonly used method to diagnose progressive periodontal disease ${ }^{181}$. Nonetheless, a change in probing depth may represent a true change in the attachment level and in the tissue tone, or a combination of both ${ }^{106}$. Widespread manifestations of active episodes of periodontal disease ${ }^{170}$ may be associated with variations in the supracrestal inflammatory cell populations, where significantly higher number of mast cells, monocytes/macrophages and plasma cells are present in active sites when compared with inactive sites ${ }^{263}$. These cells involve the active expression of both catabolic cytokines and inflammatory mediators, including interleukin-1, interleukin-6, tumor necrosis factor-a, etc., through the activation of monocytes/ macrophages, lymphocytes, fibroblasts, and other cellular elements involved. These cytokines and inflammatory mediators are capable of acting alone or together to stimulate alveolar bone resorption and collagen destruction via tissue-derived matrix metalloproteinases, a major pathway for the 
breakdown of bony and soft connective tissue, associated with periodontal activity ${ }^{119,162}$.

The theoretical manner in which periodontal disease progresses has been a subject of debate. Before the 1980 's, based on longitudinal studies ${ }^{133}$, it was assumed that a periodontal lesion progressed at a relatively constant rate, and that the progress was continuous. Estimations of $0.1 \mathrm{~mm}$ per year of attachment loss have reinforced the concept of continuous disease. As a result, it was common to report average periodontal disease progression rates in which site-specific measurements were averaged per patient, and group averages of the patients were then calculated. The acceptance of the burst theory implied that etiologic factors of periodontitis would not be continuously present (in quantity or quality sufficient to produce the disease), but would be present (in quantity or quality sufficient to produce the disease) only prior to and during the burst of the disease activity ${ }^{40}$. During progressive periodontitis, an increased number of $\mathrm{CD}^{+}$lymphocytes are detected in active periodontal lesions, compared with either inactive lesions or healthy tissues ${ }^{204}$. However, analysis of $\mathrm{T}$ lymphocyte populations by flow cytometry in progressive periodontitis reveals similar $\mathrm{CD}^{+}$/ $\mathrm{CD}^{+}$ratios between active and inactive periodontal lesions ${ }^{204}$. In this context, it could be speculated that particular T-cell phenotypes are associated to active periodontal attachment loss. In fact, an increased expression of T-bet, the master switch gene controlling the Th1 lymphocyte polarization, has been detected in active lesions when compared with inactive lesions. Furthermore this T-bet overexpression correlates positively with the increments in the expression of interleukin-1 $\beta$ and IFN- $\gamma^{45,46}$.

In progressive periodontitis, it has been difficult to determine which $\mathrm{T}$ cell subset and specific cytokine profiles are destructive and which ones are associated with disease resolution, since the presence of multiple bacteria in the subgingival biofilm, including commensal strains, can modify or even switch from a $\mathrm{T}$ cell-type of response to another ${ }^{28,118}$. Data regarding the $\mathrm{T}$-helper response associated to tissue destruction during periodontitis remains controversial. Both T-helper 1-type and T-helper 2-type immune responses have been associated with active periodontitis and stable lesions $54,141,228$. More recently, a Th17-type of response has been associated with periodontitisinduced tissue destruction $24,247,255$ and T-regulatory cells have been suggested to protect tissues against periodontitis ${ }^{24}$.

Our group has recently analyzed the role of T-helper 17 and T-regulatory phenotypes during the progression of periodontal destruction ${ }^{45}$. The over-expression of transcription factors RORC2 and Foxp3, and cytokines interleukin-17 and RANKL were associated with active periodontal lesions during progressive periodontitis. Interleukin-10 and transforming growth factor- $\beta 1$, however, were down-regulated in active periodontal lesions. In fact, these regulatory cytokines were over-regulated in inactive lesions. The analysis of the associations between the different genes yielded significant positive correlations between RORC2 and RANKL, and between RORC2 and interleukin-17; however, Foxp3, interleukin-10, transforming growth factor- $\beta 1$, and CTLA-4 did not show a positive correlation, speculating that Foxp $3^{+}$T-cells do not bear regulatory functions and may have a role in periodontal progressive destruction, due to the down-regulation of interleukin-10 and transforming growth factor- $\beta 1$. Although T-regulatory and T-helper 17 cells play different roles during the pathogenesis of infections, it has been demonstrated that there exist a reciprocal developmental pathway for their generation. Naïve $T$ cells exposed to transforming growth factor- $\beta$ up-regulate Foxp3 and become induced T-regulatory cells; however, when cultured with transforming growth factor- $\beta$ and interleukin-6, naïve $T$ cells generate T-helper 17 cells with pathologic activities ${ }^{19,259}$. Thus, when the immune response is not activated, transforming growth factor- $\beta$ favors the generation of induced T-regulatory cells, which suppress inflammation; however, when an infection is established, for instance during either gingivitis or early events of periodontitis, interleukin- 6 is synthesized during the innate immune response, inhibiting the generation of T-regulatory cells and inducing the differentiation of proinflammatory and pro-resorptive T-helper 17 cells in presence of transforming growth factor- $\beta^{18}$. Hence, T-regulatory and T-helper 17 cells may arise from the same precursor cell and selective differentiation would depend on the local cytokine milieu, which would determine the predominance of either T-regulatory cells with suppressor activity or T-helper 17 cells with pathologic activities, determining the outcome of the disease.

Our findings have demonstrated that total amount of RANKL detected in gingival crevicular fluid of patients undergoing periodontitis progression was significantly higher in active compared with inactive periodontal lesions and, thus, this proresorptive factor could be considered as a marker of active alveolar bone resorption associated with periodontal infection ${ }^{45,245}$. This finding was corroborated when cytokine mRNA analysis was performed using quantitative $\mathrm{PCR}^{45}$. In active periodontal lesions, RANKL was significantly over-expressed (3.4-fold) compared with inactive periodontal lesions. Similarly, interleukin-17 (2.8fold), interleukin-1 $\beta$ (3.7-fold) and interferon- $\gamma$ (7.8-fold) were also significantly over-expressed in active periodontal lesions. RORC2 ( 1.5 -fold) 
over-expression, however, was not statistically significant ${ }^{45}$. The analysis of correlations between RANKL and interleukin-17 with the different Thassociated transcription factors yielded positive correlation with RORC2 ( $r=0.966$ and $r=0.915$, $p<0.01$, respectively). A positive correlation was also detected between RANKL and interleukin-17 $(r=0.963, p<0.01)$.

One of the main concerns in progressive periodontitis is the definition of active periodontal lesions, where tissue destruction is taking place. An active periodontal lesion has been characterized by a prominent infiltration of activated $C D 4^{+}$ $\mathrm{T}$ cells ${ }^{204}$, which express bone destructionassociated cytokines such as interleukin-17 and RANKL $45,110,223,246,247$. Thus, the predominance of T-helper 17 over T-regulatory in active periodontal lesions would be directly associated to RANKLmediated alveolar bone destruction. All these cytokines and inflammatory mediators are capable of acting alone or in concert, to stimulate periodontal breakdown and collagen destruction via tissue-derived matrix metalloproteinases, characterizing the progression of periodontitis as a stage that presents a significantly host immune and inflammatory response to the microbial challenge that determines the susceptibility to develop destructive/progressive periodontitis under the influence of multiple behavioral, environmental and genetic factors.

\section{Concluding Remarks}

A few bacterial species in the subgingival biofilm have been associated with diseased periodontal tissues and identified as putative pathogens. It was concluded that there is strong evidence that $P$. gingivalis, $A$. actinomycetemcomitans and $T$. forsythia are periodontal pathogens when its presence is in sufficient numbers and in susceptible hosts. The bacterial composition of plaque remains relatively stable despite regular exposure to minor environmental perturbations incorporated into a new hypothesis: the ecological plaque hypothesis, to explain the relationship between the plaque microflora and the host in health and disease, and to identify new strategies for disease prevention. The recent advancements in the periodontal research field are consistent with a new model of pathogenesis, according to which periodontitis is initiated by a synergistic and dysbiotic microbial community rather than by a select bacterial complex, i.e., polymicrobial synergy and dysbiosis model (PSD model).

The innate immune response constitutes a homeostatic system, which is the first line of defense, and is able to recognize invading microorganisms as non-self, triggering immune responses to eliminate them. The effectors mechanisms of innate immune are improved by adaptive immune involving an efficient loop for microbial clearance, where triggering of proper innate mechanisms ensure an effective adaptive immune response, which potentiate these innate effectors functions against periodontopathic bacteria. The primary response to pathogens in the innate immune system is triggered by PRRs that bind PAMPs, found in a broad type of organisms. In addition to the innate immunity, adaptive immunity cells and characteristic cytokines have been described as important players in the periodontal disease pathogenesis scenario, with a special attention to $\mathrm{CD}^{+}{ }^{+} \mathrm{T}$-cells ( $\mathrm{T}$-helper cells). Interestingly, $\mathrm{T}$ cell-mediated adaptive immunity development is highly dependent on innate immunity-associated antigen presenting cells, which after antigen capture undergo into a maturation process and migrate towards the lymph nodes, where produce distinct patterns of cytokines that will contribute to the subsequent polarization and activation of specific T CD4+ lymphocyte.

Skeletal homeostasis depends on a dynamic balance between the activities of the OBLs and OCLs. This balance is tightly controlled by various regulatory systems, such as the endocrine system, and is influenced by the immune system, an osteoimmunological regulation depending on lymphocyte- and macrophage-derived cytokines. An unbalance in favor of bone-resorbing osteoclasts leads to pathological bone resorption as it has been observed in rheumatoid arthritis, osteoporosis, Paget's disease, bone tumors, and periodontitis. Diverse studies have analyzed the concentrations of RANKL and osteoprotegerin in gingival crevicular fluid of periodontitis patients and healthy subjects. In general, they show great variation from study to study, but the ratio of RANKL/osteoprotegerin has a consistent tendency to increase from periodontal health to periodontitis and to decrease following periodontal treatment.

Matrix metalloproteinases can be released and/ or activated during periodontal inflammation by proinflammatory cytokines, like tumor necrosis factor- $a$, interleukin-1 $\beta$, reactive oxygen species, and proteases derived from the subgingival biofilm and the host ${ }^{118}$. Accordingly, higher mRNA expression levels of matrix metalloproteinase/ TIMP ratios for matrix metalloproteinase-1, -2 and -9 , as well as RANKL/osteoprotegerin ratio, have been reported in gingival tissue from chronic and aggressive periodontitis patients compared with healthy gingival tissue.

Characterization of progressive lesions in chronic periodontitis patients has been controversial over time and mechanisms involved in protection versus destruction of the host's periodontium are still not fully understood. Evidence indicates that periodontal disease has dynamic states of 
exacerbation and remission, which can be described in terms of patterns of disease progression and regression. Loss of attachment recorded by sequential probing assessments is thought to reflect the cumulative effect of such repeated episodes, and represents the most commonly used method to diagnose progressive periodontal disease. Nonetheless, a change in probing depth may represent a true change in the attachment level, a change in tissue tone, or a combination of both. Widespread manifestations of active episodes of periodontal disease may be associated with variations in the supracrestal inflammatory cell populations, where significantly higher number of mast cells, monocytes/macrophages and plasma cells are present in active sites when compared with inactive sites.

\section{ACKNOWLEDGMENTS}

This study was supported by project grant 1090046 and 1130570 from the Scientific and Technologic Investigation Resource, Chile. The authors report no conflicts of interest related to this study. We thank Claudia Cristina Biguetti for her excellent artwork in the manuscript figures.

\section{REFERENCES}

1- Acosta-Rodriguez EV, Napolitani G, Lanzavecchia A, Sallusto F. Interleukins 1 beta and 6 but not transforming growth factor-beta are essential for the differentiation of interleukin 17-producing human T helper cells. Nat Immunol. 2007;8:942-9.

2- Agnello D, Lankford CS, Bream J, Morinobu A, Gadina M, O'Shea $\mathrm{J}$, et al. Cytokines and transcription factors that regulate $T$ helper cell differentiation: new players and new insights. J Clin Immunol. 2003;23:147-61.

3- Akira S, Takeda K, Kaisho T. Toll-like receptors: critical proteins linking innate and acquired immunity. Nat Immunol. 2001;2:67580.

4- Amano A. Molecular interaction of Porphyromonas gingivalis with host cells: implication for the microbial pathogenesis of periodontal disease. J Periodontol. 2003;74:90-6.

5- Amano A. Bacterial adhesins to host components in periodontitis. Periodontol 2000. 2010;52:12-37.

6- Amano A. Host-parasite interactions in periodontitis: microbial pathogenicity and innate immunity. Periodontol 2000. 2010;54:914.

7- Appay V, van Lier RA, Sallusto F, Roederer M. Phenotype and function of human $T$ lymphocyte subsets: consensus and issues. Cytometry A. 2008;73:975-83.

8- Aquino SG, Guimaraes MR, Stach-Machado DR, Silva JA, Spolidorio LC, Rossa C Jr. Differential regulation of MMP-13 expression in two models of experimentally induced periodontal disease in rats. Arch Oral Biol. 2009;54:609-17.

9- Arancibia SA, Beltrán CJ, Aguirre IM, Silva P, Peralta AL, Malinarich $F$, et al. Toll-like receptors are key participants in innate immune responses. Biol Res. 2007;40:97-112.

10- Astolfi CM, Shinohara AL, Silva RA, Santos MC, Line SR, Souza AP. Genetic polymorphisms in the MMP-1 and MMP-3 gene may contribute to chronic periodontitis in a Brazilian population. J Clin Periodontol. 2006;33:699-703.
11- Balbin M, Fueyo A, Tester AM, Pendás AM, Pitiot AS, Astudillo $A$, et al. Loss of collagenase-2 confers increased skin tumor susceptibility to male mice. Nat Genet. 2003;35:252-7.

12- Beklen A, Ainola M, Hukkanen M, Gürgan C, Sorsa T, Konttinen YT. MMPs, IL-1, and TNF are regulated by IL-17 in periodontitis. J Dent Res. 2007;86:347-51.

13- Beklen A, Hukkanen M, Richardson R, Konttinen YT. Immunohistochemical localization of Toll-like receptors 1-10 in periodontitis. Oral Microbiol Immunol. 2008;23:425-31.

14- Beklen A, Sorsa T, Konttinen YT. Toll-like receptors 2 and 5 in human gingival epithelial cells co-operate with T-cell cytokine interleukin-17. Oral Microbiol Immunol. 2009;24:38-42.

15- Belibasakis GN, Bostanci N. The RANKL-OPG system in clinical periodontology. J Clin Periodontol. 2012;39:239-48.

16- Belkaid Y, Chen W. Regulatory ripples. Nat Immunol. 2010;11:1077-8.

17- Belkaid Y, Tarbell K. Regulatory T cells in the control of hostmicroorganism interactions. Annu Rev Immunol. 2009;27:551-89. 18- Bettelli E, Carrier Y, Gao W, Korn T, Strom TB, Oukka M, et al. Reciprocal developmental pathways for the generation of pathogenic effector TH17 and regulatory T cells. Nature. 2006;441:235-8.

19- Bettelli E, Oukka M, Kuchroo VK. T(H)-17 cells in the circle of immunity and autoimmunity. Nat Immunol. 2007;8:345-50.

20- Bluestone JA, Mackay CR, O'Shea JJ, Stockinger B. The functional plasticity of T cell subsets. Nat Rev Immunol. 2009;9:811-6.

21- Botero J, Contreras A, Lafaurie G, Jaramillo A, Betancourt M, Arce RM. Occurrence of periodontopathic and superinfecting bacteria in chronic and aggressive periodontitis subjects in a Colombian population. J Periodontol. 2007;78:696-704.

22- Boyle WJ, Simonet WS, Lacey DL. Osteoclast differentiation and activation. Nature. 2003;423:337-42.

23- Buduneli N, Kinane DF. Host-derived diagnostic markers related to soft tissue destruction and bone degradation in periodontitis. J Clin Periodontol. 2011;38;85-105.

24- Cardoso CR, Garlet GP, Crippa GE, Rosa AL, Júnior WM, Rossi $M A$, et al. Evidence of the presence of $T$ helper type 17 cells in chronic lesions of human periodontal disease. Oral Microbiol Immunol. 2009;24:1-6.

25- Cardoso CR, Garlet GP, Moreira AP, Júnior WM, Rossi MA, Silva JS. Characterization of $\mathrm{CD} 4+\mathrm{CD} 25+$ natural regulatory $T$ cells in the inflammatory infiltrate of human chronic periodontitis. J Leukoc Biol. 2008;84:311-8.

26- Carter NA, Vasconcellos R, Rosser EC, Tulone C, Muñoz-Suano $A$, Kamanaka $M$, et al. Mice lacking endogenous IL-10-producing regulatory $B$ cells develop exacerbated disease and present with an increased frequency of Th1/Th17 but a decrease in regulatory T cells. J Immunol. 2011;186:5569-79.

27- Chabaud M, Durand JM, Buchs N, Fossiez F, Page G, Frappart $L$, et al. Human interleukin-17: a $T$ cell-derived proinflammatory cytokine produced by the rheumatoid synovium. Arthritis Rheum. 1999;42:963-70.

28- Choi J, Borrello MA, Smith E, Cutler CW, Sojar H, Zauderer M. Prior exposure of mice to Fusobacterium nucleatum modulates host response to Porphyromonas gingivalis. Oral Microbiol Immunol. 2001;16:338-44.

29- Claudino M, Garlet TP, Cardoso CR, Assis GF, Taga R, Cunha FQ, et al. Down-regulation of expression of osteoblast and osteocyte markers in periodontal tissues associated with the spontaneous alveolar bone loss of interleukin-10 knockout mice. Eur J Oral Sci. 2010;118:19-28.

30- Colić M, Gazivoda D, Vucević D, Vasilijić S, Rudolf R, Lukić A. Proinflammatory and immunoregulatory mechanisms in periapical lesions. Mol Immunol. 2009;47;101-13.

31- Consensus report. Periodontal diseases: pathogenesis and microbial factors. Ann Periodontol. 1996;1:926-32.

32- Contreras A, Nowzari $H$, Slots J. Herpesvirus in periodontal pocket and gingival tissue specimens. Oral Microbiol Immunol. 2000;15:15-8. 
33- Contreras A, Umeda M, Chen C, Bakker I, Morrison JL, Slots J. Relationship between herpesvirus and adult periodontitis and periodontopathic bacteria. J Periodontol. 1999;70:478-84.

34- Correa FO, Gonçalves D, Figueredo CM, Gustafsson A, Orrico SR. The short-term effectiveness of non-surgical treatment in reducing levels of interleukin-1beta and proteases in gingival crevicular fluid from patients with type 2 diabetes mellitus and chronic periodontitis. J Periodontol. 2008;79:2143-50.

35- Cortelli JR, Cortelli SC, Jordan S, Haraszthy VI, Zambon J]. Prevalence of periodontal pathogens in Brazilians with aggressive or chronic periodontitis. J Clin Periodontol. 2005;32:860-6.

36- Costa PP, Trevisan GL, Macedo GO, Palioto DB, Souza SL, Grisi MF, et al. Salivary interleukin-6, matrix metalloproteinase-8, and osteoprotegerin in patients with periodontitis and diabetes. J Periodontol. 2010;81:384-91.

37- Crotti T, Smith MD, Hirsch R, Soukoulis S, Weedon $H_{\text {, }}$ Capone $\mathrm{M}$, et al Receptor activator NF kappaB ligand (RANKL) and osteoprotegerin (OPG) protein expression in periodontitis. J Periodontal Res. 2003;38:380-7.

38- Cutler CW, Jotwani R. Antigen-presentation and the role of dendritic cells in periodontitis. Periodontol 2000. 2004;35:135-57. 39- Dennison DK, Van Dyke TE. The acute inflammatory response and the role of phagocytic cells in periodontal health and disease. Periodontol 2000. 1997;14:54-78.

40- DeRouen TA, Hujoel PP, Mancl LA. Statistical issues in periodontal research. J Dent Res. 1995;74:1731-7.

41- Dewhirst FE, Stashenko PP, Mole JE, Tsurumachi T. Purification and partial sequence of human osteoclast-activating factor: identity with interleukin 1 beta. J Immunol. 1985;135:2562-8.

42- Dixon DR, Darveau RP. Lipopolysaccharide heterogeneity: innate host responses to bacterial modification of lipid a structure. J Dent Res. 2005;84:584-95.

43- Dong C. Diversification of T-helper-cell lineages: finding the family root of IL-17-producing cells. Nature Reviews. 2006;6:32933.

44- Dong, C. TH17 cells in development: an updated view of their molecular identity and genetic programming. Nat Rev Immunol. 2008;8:337-48.

45- Dutzan N, Gamonal J, Silva A, Sanz M, Vernal, R. Overexpression of forkhead box $\mathrm{P} 3$ and its association with receptor activator of nuclear factor-kappa B ligand, interleukin (IL) -17, IL10 and transforming growth factor-beta during the progression of chronic periodontitis. J Clin Periodontol. 2009;36:396-403.

46- Dutzan N, Vernal R, Hernandez M, Dezerega A, Rivera O, Silva $\mathrm{N}$, et al. Levels of interferon-gamma and transcription factor T-bet in progressive periodontal lesions in patients with chronic periodontitis. J Periodontol. 2009;80:290-6.

47- Eastcott JW, Yamashita K, Taubman MA, Harada Y, Smith DJ. Adoptive transfer of cloned $T$ helper cells ameliorates periodontal disease in nude rats. Oral Microbiol Immunol. 1994;9:284-9.

48- Ejeil AL, Igondjo-Tchen S, Ghomrasseni S, Pellat B, Godeau G, Gogly B. Expression of matrix metalloproteinases (MMPs) and tissue inhibitors of metalloproteinases (TIMPs) in healthy and diseased human gingiva. J Periodontol. 2003;74:188-95.

49- Elyaman W, Bradshaw EM, Uyttenhove C, Dardalhon V, Awasthi A, Imitola J, et al. IL-9 induces differentiation of TH17 cells and enhances function of FoxP3+ natural regulatory T cells. Proc Natl Acad Sci U S A. 2009;106:12885-90.

50- Farquharson SI, Germaine GR, Gray GR. Isolation and characterization of the cell-surface polysaccharides of Porphyromonas gingivalis ATCC 53978. Oral Microbiol Immunol. 2000;15:151-7. 51- Fine DH, Kaplan JB, Kachlany SC, Schreiner HC. How we got attached to Actinobacillus actinomycetemcomitans: a model for infectious diseases. Periodontol 2000. 2006;42:114-57.

52- Folgueras AR, Pendás AM, Sánchez LM, López-Otín C. Matrix metalloproteinases in cancer: from new functions to improved inhibition strategies. Int J Dev Biol. 2004;48:411-24.

53- Ford PJ, Gamonal J, Seymour GJ. Immunological differences and similarities between chronic periodontitis and aggressive periodontitis. Periodontol 2000. 2010;53:111-23.
54- Gaffen SL, Hajishengallis G. A new inflammatory cytokine on the block: re-thinking periodontal disease and the Th1/Th2 paradigm in the context of Th17 cells and IL-17. J Dent Res. 2008;87:817-28. 55- Gajardo M, Silva N, Gómez L, León R, Parra B, Contreras A, et al. Prevalence of periodontopathic bacteria in aggressive periodontitis patients in a chilean population. J Periodontol. 2005;76:289-94. 56- Gamonal J, Sanz M, O'Connor A, Acevedo A, Suarez I, Sanz A, et al. Delayed neutrophil apoptosis in chronic periodontitis patients. J Clin Periodontol. 2003;30:616-23.

57- Gao Y, Grassi F, Ryan MR, Terauchi M, Page K, Yang X, et al. IFN-gamma stimulates osteoclast formation and bone loss in vivo via antigen-driven T cell activation. J Clin Invest. 2007;117:122-32. 58- Garlet GP, Cardoso CR, Campanelli AP, Garlet TP, Ávila-Campos $\mathrm{MJ}$, Cunha FQ, et al. The essential role of IFN-gamma in the control of lethal Aggregatibacter actinomycetemcomitans infection in mice. Microbes Infect. 2008;10:489-96.

59- Garlet GP, Cardoso CR, Mariano FS, Claudino M, Assis GF, Campanelli AP, et al. Regulatory $\mathrm{T}$ cells attenuate experimental periodontitis progression in mice. J Clin Periodontol. 2010;37:591600.

60- Garlet GP, Cardoso CR, Silva TA, Ferreira BR, Avila-Campos $\mathrm{MJ}$, Cunha FQ, et al. Cytokine pattern determines the progression of experimental periodontal disease induced by Actinobacillus actinomycetemcomitans through the modulation of MMPs, RANKL, and their physiological inhibitors. Oral Microbiol Immunol. 2006;21:12-20.

61- Garlet GP, Martins W Jr, Ferreira BR, Milanezi CM, Silva JS. Patterns of chemokines and chemokine receptors expression in different forms of human periodontal disease. J Periodontal Res. 2003;38:210-7.

62- Garlet GP, Martins W Jr, Fonseca BA, Ferreira BR, Silva JS. Matrix metalloproteinases, their physiological inhibitors and osteoclast factors are differentially regulated by the cytokine profile in human periodontal disease. J Clin Periodontol. 2004;31:671-9.

63- Garlet TP, Coelho U, Repeke CE, Silva JS, Cunha FQ, Garlet GP. Differential expression of osteoblast and osteoclast chemmoatractants in compression and tension sides during orthodontic movement. Cytokine. 2008;42:330-5.

64- Gelani V, Fernandes AP, Gasparoto TH, Garlet TP, Cestari TM, Lima HR, et al. The role of toll-like receptor 2 in the recognition of Aggregatibacter actinomycetemcomitans. J Periodontol. 2009;80:2010-9.

65- Gemmell E, Yamazaki K, Seymour GJ. Destructive periodontitis lesions are determined by the nature of the lymphocytic response. Crit Rev Oral Biol Med. 2002;13:17-34.

66- Gemmell E, Yamazaki K, Seymour GJ. The role of T cells in periodontal disease: homeostasis and autoimmunity. Periodontol 2000. 2007;43:14-40.

67- Giannopoulou C, Kamma JJ, Mombelli A. Effect of inflammation, smoking and stress on gingival crevicular fluid cytokine level. J Clin Periodontol. 2003;30:145-53.

68- Golub LM, Lee HM, Greenwald RA, Ryan ME, Sorsa T, Salo $T$, et al. A matrix metalloproteinase inhibitor reduces bone-type collagen degradation fragments and specific collagenases in gingival crevicular fluid during adult periodontitis. Inflamm Res. 1997;46:310-9.

69- Golub LM, Lee HM, Stoner JA, Sorsa T, Reinhardt RA, Wolff MS, et al. Subantimicrobial-dose doxycycline modulates gingival crevicular fluid biomarkers of periodontitis in postmenopausal osteopenic women. J Periodontol. 2008;79:1409-18.

70- Goodson JM, Haffajee AD, Socransky SS. The relationship between attachment level loss and alveolar bone loss. J Clin Periodontol. 1984;11:348-59.

71- Goodson JM, Tanner AC, Haffajee AD, Sornberger GC, Socransky SS. Patterns of progression and regression of advanced destructive periodontal disease. J Clin Periodontol. 1982;9:472-81.

72- Graves D. Cytokines that promote periodontal tissue destruction. J Periodontol. 2008;79:1585-91. 
73- Graves DT, Oates T, Garlet GP. Review of osteoimmunology and the host response in endodontic and periodontal lesions. J Oral Microbiol. 2011;17;3.

74- Grivel JC, Santoro F, Chen S, Fagá G, Malnati MS, Ito Y, et al. Pathogenic effects of human herpesvirus 6 in human lymphoid tissue ex vivo. J Virol. 2003;77:8280-9.

75- Guentsch A, Puklo M, Preshaw PM, Glockmann E, Pfister W, Potempa J, et al. Neutrophils in chronic and aggressive periodontitis in interaction with Porphyromonas gingivalis and Aggregatibacter actinomycetemcomitans. J Periodontal Res. 2009;44:368-77.

76- Gürkan A, Emingil G, Saygan BH, Atilla G, Cinarcik S, Köse T, et al. Gene polymorphisms of matrix metalloproteinase-2, -9 and -12 in periodontal health and severe chronic periodontitis. Arch Oral Biol. 2008;53:337-45.

77- Gürsoy M, Könönen E, Gürsoy UK, Tervahartiala T, Pajukanta $\mathrm{R}$, Sorsa, T. Periodontal status and neutrophilic enzyme levels in gingival crevicular fluid during pregnancy and postpartum. ] Periodontol. 2010;81:1790-6.

78- Gutiérrez-Fernández, A, Inada M, Balbín M, Fueyo A, Pitiot AS, Astudillo $A$, et al. Increased inflammation delays wound healing in mice deficient in collagenase-2 (MMP-8). FASEB J. 2007;21:258091.

79- Hajishengallis G, Lamont RJ. Beyond the red complex and into more complexity: the polymicrobial synergy and dysbiosis (PSD) model of periodontal disease etiology. Mol Microbiol. 2012;27:40919.

80- Hajishengallis G, Wang M, Liang S, Triantafilou M, Triantafilou K. Pathogen induction of CXCR4/TLR2 cross-talk impairs host defense function. Proc Natl Acad Sci U S A. 2008;105:13532-7.

81- Hamlet SM, Ganashan N, Cullinan MP, Westerman B, Palmer JE, Seymour GJ. A 5-year longitudinal study of Tannerella forsythia prtH Genotype: association with loss of attachment. J Periodontol. 2008;79:144-9.

82- Hasegawa Y, Tribble GD, Baker HV, Mans JJ, Handfield M, Lamont RJ. Role of Porphyromonas gingivalis SerB in gingival epithelial cell cytoskeletal remodeling and cytokine production. Infect Immun. 2008; 76:2420-7.

83- Heikkinen AM, Sorsa T, Pitkäniemi J, Tervahartiala T, Kari K, Broms $U$, et al. Smoking affects diagnostic salivary periodontal disease biomarker levels in adolescents. J Periodontol. 2010;81:1299-1307.

84- Hernández M, Dutzan N, García-Sesnich J, Abusleme L, Dezerega A, Silva N, et al. Host-pathogen interactions in progressive chronic periodontitis. J Dent Res. 2011;90:1164-70.

85- Hernández M, Gamonal J, Salo T, Tervahartiala T, Hukkanen $M$, Tjäderhane $L$, et al. Reduced expression of lipopolysaccharideinduced CXC chemokine in Porphyromonas gingivalis-induced experimental periodontitis in matrix metalloproteinase-8 null mice. J Periodontal Res. 2011;46:58-66.

86- Hernández M, Gamonal J, Tervahartiala T, Mäntylä P, Rivera O, Dezerega A, et al. Associations between matrix metalloproteinase-8 and -14 and myeloperoxidase in gingival crevicular fluid from subjects with progressive chronic periodontitis: a longitudinal study. J Periodontol. 2010;81:1644-52.

87- Hernández M, Martínez B, Tejerina JM, Valenzuela MA, Gamonal J. MMP-13 and TIMP-1 determinations in progressive chronic periodontitis. J Clin Periodontol. 2007;34:729-35.

88- Hernandez M, Valenzuela MA, Lopez-Otin C, Alvarez J, Lopez JM, Vernal R, et al. Matrix metalloproteinase-13 is highly expressed in destructive periodontal disease activity. J Periodontol. 2006;77:1863-70.

89- Hernández Ríos M, Sorsa T, Obregón F, Tervahartiala $T$, Valenzuela MA, Pozo $P$, et al. Proteolytic roles of matrix metalloproteinase (MMP)-13 during progression of chronic periodontitis: initial evidence for MMP-13/MMP-9 activation cascade. J Clin Periodontol. 2009;36:1011-7.

90- Herrera D, Contreras A, Gamonal J, Oteo A, Jaramillo A, Silva N, et al. Subgingival microbial profiles in chronic periodontitis patients from Chile, Colombia and Spain. J Clin Periodontol. 2008;35;106-13.
91- Hofbauer LC, Heufelder AE. Role of receptor activator of nuclear factor-kappaB ligand and osteoprotegerin in bone cell biology. J Mol Med (Berl). 2001;79:243-53.

92- Holla LI, Fassmann A, Muzik J, Vanek J, Vasku A. Functional polymorphisms In the matrix metalloproteinase- 9 gene in relation to severity of chronic periodontitis. J Periodontol. 2006;77:1850-5. 93- Holt SC, Kesavalu L, Walker S, Genco CA Virulence factors of Porphyromonas gingivalis. Periodontol 2000. 1999;20:168-238. 94- Honda T, Domon H, Okui T, Kajita K, Amanuma R, Yamazaki $K$. Balance of inflammatory response in stable gingivitis and progressive periodontitis lesions. Clin Exp Immunol. 2006;144:3540.

95- Hong $\mathrm{MH}$, Williams $\mathrm{H}$, Jin $\mathrm{CH}$, Pike JW. The inhibitory effect of interleukin-10 on mouse osteoclast formation involves novel tyrosine-phosphorylated proteins. J Bone Miner Res. 2000;15:9118.

96- Horton JE, Raisz LG, Simmons HA, Oppenheim JJ, Mergenhagen SE. Bone resorbing activity in supernatant fluid from cultured human peripheral blood leukocytes. Science. 1972;177:793-5.

97- Huang L, Xu J, Wood DJ, Zheng MH. Gene expression of osteoprotegerin ligand, osteoprotegerin, and receptor activator of NF-kappaB in giant cell tumor of bone: possible involvement in tumor cell-induced osteoclast-like cell formation. Am J Pathol. 2000;156:761-7.

98- Ihn H, Yamane K, Asano Y, Kubo M, Tamaki K. IL-4 up-regulates the expression of tissue inhibitor of metalloproteinase- 2 in dermal fibroblasts via the p38 mitogen-activated protein kinase dependent pathway. J Immunol. 2002;168:1895-902.

99- Ilgenli T, Vardar-Sengul S, Gürkan A, Sorsa T, Stackelberg S, Köse $T$, et al. Gingival crevicular fluid matrix metalloproteinase-13 levels and molecular forms in various types of periodontal diseases. Oral Dis. 2006;12:573-9.

100- Imamura T. The role of gingipains in the pathogenesis of periodontal disease. J Periodontol. 2003;74:111-8.

101- Isaza-Guzmán DM, Arias-Osorio C, Martínez-Pabón MC, Tobón-Arroyave SI. Salivary levels of matrix metalloproteinase (MMP)-9 and tissue inhibitor of matrix metalloproteinase (TIMP)1: a pilot study about the relationship with periodontal status and MMP-9(-1562C/T) gene promoter polymorphism. Arch Oral Biol. 2011;56:401-11.

102- Izakovicova Holla L, Hrdlickova B, Vokurka J, Fassmann A. Matrix metalloproteinase 8 (MMP8) gene polymorphisms in chronic periodontitis. Arch Oral Biol. 2012;57:188-96.

103- Jager A, Kuchroo VK. Effector and regulatory T-cell subsets in autoimmunity and tissue inflammation. Scand J Immunol. 2010;72:173-84.

104- Jain S, Darveau RP. Contribution of Porphyromonas gingivalis lipopolysaccharide to periodontitis. Periodontol 2000. 2010;54(1):53-70.

105- Jarnicki AG, Fallon PG. T helper type-2 cytokine responses: potential therapeutic targets. Curr Opin Pharmacol. 2003;3:449-55. 106- Jeffcoat MK, Reddy MS. Progression of probing attachment loss in adult periodontitis. J Periodontol. 1991;62:185-9.

107- Kachlany SC. Aggregatibacter actinomycetemcomitans leukotoxin: from threat to therapy. J Dent Res. 2010;89:561-70. 108- Kalinski P. Moser M. Consensual immunity: success-driven development of T-helper-1 and T-helper- 2 responses. Nat Rev Immunol. 2005;5:251-60.

109- Kawai T, Eisen-Lev R, Seki M, Eastcott JW, Wilson ME, Taubman MA. Requirement of B7 costimulation for Th1-mediated inflammatory bone resorption in experimental periodontal disease. J Immunol. 2000;164:2102-9.

110- Kawai T, Matsuyama T, Hosokawa Y, Makihira S, Seki M, Karimbux NY, et al. B and T lymphocytes are the primary sources of RANKL in the bone resorptive lesion of periodontal disease. Am J Pathol. 2006;169:987-98. 
111- Kiili M, Cox SW, Chen HY, Wahlgren J, Maisi P, Eley BM, et al. Collagenase-2 (MMP-8) and collagenase-3 (MMP-13) in adult periodontitis: molecular forms and levels in gingival crevicular fluid and immunolocalisation in gingival tissue. J Clin Periodontol. 2002;29:224-32.

112- Kikkert R, Laine ML, Aarden LA, van Winkelhoff AJ. Activation of toll-like receptors 2 and 4 by gram-negative periodontal bacteria. Oral Microbiol Immunol. 2007;22:145-51.

113- Kinane DF, Demuth DR, Gorr SU, Hajishengallis GN, Martin $\mathrm{MH}$. Human variability in innate immunity. Periodontol 2000. 2007;45:14-34.

114- Knäuper V, Smith B, López-Otin C, Murphy G. Activation of progelatinase $B$ (proMMP-9) by active collagenase-3 (MMP-13). Eur J Biochem. 1997;248:369-73.

115- Knäuper V, Will H, López-Otin C, Smith B, Atkinson SJ, Stanton $\mathrm{H}$, et al. Cellular mechanisms for human procollagenase-3 (MMP13) activation. Evidence that MT1-MMP (MMP-14) and gelatinase a (MMP-2) are able to generate active enzyme. J Biol Chem. 1996;271:17124-31.

116- Kolodrubetz D, Dailey T, Ebersole J, Kraig E. Cloning and expression of the leukotoxin gene from Actinobacillus actinomycetemcomitans. Infect Immun. 1989;57:1465-9.

117- Kong YY, Feige U, Sarosi I, Bolon B, Tafuri A, Morony S, et al. Activated T cells regulate bone loss and joint destruction in adjuvant arthritis through osteoprotegerin ligand. Nature. 1999;402:304-9. 118- Kopitar AN, Ihan Hren N, Ihan A. Commensal oral bacteria antigens prime human dendritic cells to induce Th1, Th2 or Treg differentiation. Oral Microbiol Immunol. 2006;21:1-5.

119- Kornman KS, Page RC, Tonetti MS. The host response to the microbial challenge in periodontitis: assembling the players. Periodontol 2000. 1997;14:33-53.

120- Kotake S, Udagawa N, Takahashi N, Matsuzaki K, Itoh K, Ishiyama $\mathrm{S}$, et al. IL-17 in synovial fluids from patients with rheumatoid arthritis is a potent stimulator of osteoclastogenesis. J Clin Invest. 1999;103:1345-52.

121- Kowolik MJ, Grant M. Myeloperoxidase activity in human gingival crevicular neutrophils. Arch Oral Biol. 1983;28:293-5.

122- Koziel J, Karim AY, Przybyszewska K, Ksiazek IM, Rapala-Kozik $M$, Nguyen KA, et al. Proteolytic inactivation of LL-37 by karilysin, a novel virulence mechanism of Tannerella forsythia. J Innate Immun. 2010;2:288-93.

123- Kuula H, Salo T, Pirilä E, Tuomainen AM, Jauhiainen M, Uitto $\mathrm{VJ}$, et al. Local and systemic responses in matrix metalloproteinase 8-deficient mice during Porphyromonas gingivalis-induced periodontitis. Infect Immun. 2009;77:850-9.

124- Lacey DL, Timms E, Tan HL, Kelley MJ, Dunstan CR, Burgess T, et al. Osteoprotegerin ligand is a cytokine that regulates osteoclast differentiation and activation. Cell. 1998;93:165-76.

125- Laine ML, Appelmelk BJ, van Winkelhoff AJ .Novel polysaccharide capsular serotypes in Porphyromonas gingivalis. J Periodontal Res. 1996;31:278-84.

126- Lally ET, Golub EE, Kieba IR, Taichman NS, Rosenbloom J, Rosenbloom JC, et al. Analysis of the Actinobacillus actinomycetemcomitans leukotoxin gene. Delineation of unique features and comparison to homologous toxins. J Biol Chem. 1989;264:15451-6.

127- Lappin DF, MacLeod CP, Kerr A, Mitchell T, Kinane DF. Anti-inflammatory cytokine IL-10 and T cell cytokine profile in periodontitis granulation tissue. Clin Exp Immunol. 2001;123:294300.

128- Leppilahti JM, Ahonen MM, Hernández M, Munjal S, Netuschil $\mathrm{L}$, Uitto $\mathrm{VJ}$, et al. Oral rinse MMP-8 point-of-care immuno test identifies patients with strong periodontal inflammatory burden. Oral Dis. 2011;17:115-22.

129- Li H, Rostami A. IL-9: basic biology, signaling pathways in CD4+ T cells and implications for autoimmunity. J Neuroimmune Pharmacol. 2010;5:198-209.
130- Liang S, Krauss JL, Domon H, McIntosh ML, Hosur KB, Qu $\mathrm{H}$, et al. The C5a receptor impairs IL-12-dependent clearance of Porphyromonas gingivalis and is required for induction of periodontal bone loss. J Immunol. 2011;186:869-77.

131- Lima HR, Gelani V, Fernandes AP, Gasparoto TH, Torres SA, Santos $C F$, et al. The essential role of toll like receptor- 4 in the control of Aggregatibacter actinomycetemcomitans infection in mice. J Clin Periodontol. 2010;37:248-54.

132- Liu D, Xu JK, Figliomeni L, Huang L, Pavlos NJ, Rogers M, et al. Expression of RANKL and OPG mRNA in periodontal disease: possible involvement in bone destruction. Int J Mol Med. 2003;11:17-21. 133- Löe $H$, Anerud $A$, Boysen $H$, Smith $M$. The natural history of periodontal disease in man. The rate of periodontal destruction before 40 years of age. J Periodontol. 1978;49:607-20.

134- López NJ. Occurrence of Actinobacillus actinomycetemcomitans, Porphyromonas gingivalis and Prevotella intermedia in progressive adult periodontitis. J Periodontol. 2000;71:948-54.

135- López NJ, Mellado JC, Giglio MS, Leighton GX. Occurrence of certain bacterial species and morphotypes in juvenile periodontitis in Chile. J Periodontol. 1995;66:559-67.

136- López NJ, Mellado JC, Leighton GX. Occurrence of Actinobacillus actinomycetemcomitans, Prophyromonas gingivalis and Prevotella intermedia in juvenile periodontitis. J Clin Periodontol. 1996;23:101-5.

137- López NJ, Socransky S, Silva I, Japlit MR, Haffajee A. Subgingival microbiota of chilean patients with chronic periodontitis. J Periodontol. 2004;75:717-25.

138- Lubberts E. IL-17/Th17 targeting: on the road to prevent chronic destructive arthritis? Cytokine. 2008;41:84-91.

139- Mäkelä M, Salo T, Uitto VJ, Larjava H. Matrix metalloproteinases (MMP-2 and MMP-9) of the oral cavity: cellular origin and relationship to periodontal status. J Dent Res. 1994;73:1397-406. 140- Mangan PR, Harrington LE, O'Quinn DB, Helms WS, Bullard $\mathrm{DC}$, Elson $\mathrm{CO}$, et al. Transforming growth factor-beta induces development of the $T(H) 17$ lineage. Nature. 2006;441:231-4.

141- Manhart SS, Reinhardt RA, Payne JB, Seymour GJ, Gemmell E, Dyer JK, et al. Gingival cell IL-2 and IL-4 in early-onset periodontitis. J Periodontol. 1994;65:807-13.

142- Mäntylä $P$, Stenman $M$, Kinane $D$, Salo $T$, Suomalainen $\mathrm{K}$, Tikanoja S, et al. Monitoring periodontal disease status in smokers and nonsmokers using a gingival crevicular fluid matrix metalloproteinase-8-specific chair-side test. J Periodontal Res. 2006;41:503-12.

143- Mäntylä P, Stenman M, Kinane DF, Tikanoja S, Luoto H, Salo $T$, et al. Gingival crevicular fluid collagenase-2 (MMP-8) test stick for chair-side monitoring of periodontitis. J Periodontal Res. 2003;38:436-9.

144- Marcaccini AM, Meschiari CA, Zuardi LR, Sousa TS, Taba M Jr, Teofilo JM, et al. Gingival crevicular fluid levels of MMP-8, MMP9, TIMP-2, and MPO decrease after periodontal therapy. J Clin Periodontol. 2010;37:180-90.

145- Marsh PD. Microbial ecology of dental plaque and its significance in health and disease. Adv Dent Res. 1994;8:263-71. 146- Martinelli S, Urosevic M, Daryadel A, Oberholzer PA, Baumann $C$, Fey MF, et al. Induction of genes mediating interferon-dependent extracellular trap formation during neutrophil differentiation. J Biol Chem. 2004;279:44123-32.

147- Menezes R, Garlet TP, Letra A, Bramante CM, Campanelli AP, Figueira RC, et al. Differential patterns of receptor activator of nuclear factor kappa B ligand/osteoprotegerin expression in human periapical granulomas: possible association with progressive or stable nature of the lesions. J Endod. 2008;34:932-8.

148- Missailidis CG, Umeda JE, Ota-Tsuzuki C, Anzai D, Mayer MP. Distribution of fimA genotypes of Porphyromonas gingivalis in subjects with various periodontal conditions. Oral Microbiol Immunol. 2004;19:224-9.

149- Miura M, Hamachi T, Fujise O, Maeda K. The prevalence and pathogenic differences of Porphyromonas gingivalis fimA genotypes in patients with aggressive periodontitis. J Periodontal Res. 2005;40:147-52. 
150- Miyara M, Sakaguchi S. Human FoxP3(+)CD4(+) regulatory T cells: their knowns and unknowns. Immunol Cell Biol. 2011;89:34651.

151- Mombelli A, Casagni F, Madianos. Can the presence or absence of periodontal pathogens distinguish between subjects with chronic and aggressive periodontitis? A systematic review. J Clin Periodontol. 2002;29:10-21.

152- Mori Y, Yoshimura A, Ukai T, Lien E, Espevik T, Hara Y. Immunohistochemical localization of Toll-like receptors 2 and 4 in gingival tissue from patients with periodontitis. Oral Microbiol Immunol. 2003;18:54-8.

153- Mosmann TR, Sad S. The expanding universe of T-cell subsets: Th1, Th2 and more. Immunol Today. 1996;17:138-46.

154- Mucida D, Cheroutre $\mathrm{H}$. The many face-lifts of CD4 T helper cells. Adv Immunol. 2010;107:139-52.

155- Murphy KM, Reiner SL. The lineage decisions of helper T cells. Nat Rev Immunol. 2002;2:933-44.

156- Nagasawa T, Kiji M, Yashiro R, Hormdee D, Lu H, Kunze M, et al. Roles of receptor activator of nuclear factor-kappaB ligand (RANKL) and osteoprotegerin in periodontal health and disease. Periodontol 2000. 2007;43:65-84.

157- Nakagawa I, Amano A, Ohara-Nemoto $Y$, Endoh N, Morisaki I, Kimura S, et al. Identification of a new variant of fimA gene of Porphyromonas gingivalis and its distribution in adults and disabled populations with periodontitis. J Periodontal Res. 2002;37:425-32. 158- Nakajima T, Ueki-Maruyama K, Oda T, Ohsawa $Y$, Ito $H$, Seymour GJ, et al. Regulatory T-cells infiltrate periodontal disease tissues. J Dent Res. 2005;84:639-43.

159- Nannuru KC, Futakuchi M, Varney ML, Vincent TM, Marcusson EG, Singh RK. Matrix metalloproteinase (MMP)-13 regulates mammary tumor-induced osteolysis by activating MMP9 and transforming growth factor-beta signaling at the tumor-bone interface. Cancer Res. 2010;70:3494-504.

160- Nilsson UW, Jonsson JA, Dabrosin C. Tamoxifen decreases extracellular TGF-beta1 secreted from breast cancer cells - a posttranslational regulation involving matrix metalloproteinase activity. Exp Cell Res. 2009;315:1-9.

161- Nowak EC, Weaver CT, Turner H, Begum-Haque S, Becher B, Schreiner B, et al. IL-9 as a mediator of Th17-driven inflammatory disease. J Exp Med. 2009;206:1653-60.

162- Offenbacher S. Periodontal diseases: pathogenesis. Ann Periodontol. 1996;1:821-78.

163- Ohyama H, Kato-Kogoe N, Kuhara A, Nishimura F, Nakasho K, Yamanegi $\mathrm{K}$, et al. The involvement of IL-23 and the Th17 pathway in periodontitis. J Dent Res. 2009;88:633-8.

164- Ohyama H, Matsushita S, Kato N, Nishimura F, Oyaizu K, Kokeguchi $S$, et al. T cell responses to $53-k D a$ outer membrane proteína of Porphyromonas gingivalis in humans with early-onset periodontitis. Y. Hum Immunol. 1998;59(10):635-43.

165- Okada $\mathrm{H}$, Murakami S. Cytokine expression in periodontal health and disease. Crit Rev Oral Biol Med. 1998;9:248-66.

166- Oseko F, Yamamoto T, Akamatsu Y, Kanamura N, Iwakura Y, Imanishi J, et al. IL-17 is involved in bone resorption in mouse periapical lesions. Microbiol Immunol. 2009;53:287-94.

167- Overall CM. Molecular determinants of metalloproteinase substrate specificity: matrix metalloproteinase substrate binding domains, modules, and exosites. Mol Biotechnol. 2002;22:51-86. 168- Oyarzun A, Arancibia R, Hidalgo R, Penafiel C, Caceres M, Gonzalez MJ, et al. Involvement of MT1-MMP and TIMP-2 in human periodontal disease. Oral Dis. 2010;16:388-95.

169- Page RC, Lantz MS, Darveau R, Jeffcoat M, Mancl L, Houston $L$, et al. Immunization of Macaca fascicularis against experimenta periodontitis using a vaccine containing cysteine proteases purified from Porphyromonas gingivalis. Oral Microbiol Immunol. 2007;22:162-8.

170- Papapanou PN, Wennström JL, Gröndahl K. A 10-year retrospective study of periodontal disease progression. J Clin Periodontol. 1989;16:403-11.
171- Paster BJ, Boches SK, Galvin JL, Ericson RE, Lau CN, Levanos $V A$, et al. Bacterial diversity in human subgingival plaque. J Bacteriol. 2001;183:3770-83.

172- Pestka S, Krause CD, Sarkar D, Walter MR, Shi Y, Fisher PB. Interleukin-10 and related cytokines and receptors. Annu Rev Immunol. 2004;22:929-79.

173- Pihlstrom BL, Michalowicz BS, Johnson NW. Periodontal diseases. Lancet. 2005;366:1809-20.

174- Pirhan D, Atilla G, Emingil G, Sorsa T, Tervahartiala T, Berdeli A. Effect of MMP-1 promoter polymorphisms on GCF MMP-1 levels and outcome of periodontal therapy in patients with severe chronic periodontitis. J Clin Periodontol. 2008;35:862-70.

175- Pirhan D, Atilla G, Emingil G, Tervahartiala T, Sorsa T, Berdeli A. MMP-13 promoter polymorphisms in patients with chronic periodontitis: effects on GCF MMP-13 levels and outcome of periodontal therapy. J Clin Periodontol. 2009;36:474-81.

176- Potempa J, Pike R., Travis J. The multiple forms of tripsin-like activity present in various strains of Porphyromonas gingivalis are due to the presence of either Arg-gingipain or Lys-gingipain. Infect Inmun. 1995;63:1176-82.

177- Potempa J, Pike R, Travis J. Titration and mapping of the active sites of cysteina-proteinases from Porphyromonas gingivalis (gingipains) using peptidylchloromethanes. Biol Chem. 1997; 378:223-30.

178- Pozo P, Valenzuela MA, Melej C, Zaldívar M, Puente J, Martínez $B$, et al. Longitudinal analysis of metalloproteinases, tissue inhibitors of metalloproteinases and clinical parameters in gingival crevicular fluid from periodontitis-affected patients. J Periodontal Res. 2005;40:199-207.

179- Pradeep AR, Roopa Y, Swati PP. Interleukin-4, a T-helper 2 cell cytokine, is associated with the remission of periodontal disease. J Periodontal Res. 2008;43:712-6.

180- Queiroz-Junior CM, Silva MJ, Corrêa JD, Madeira MF, Garlet TP, Garlet GP, et al. A controversial role for IL-12 in immune response and bone resorption at apical periodontal sites. Clin Dev Immunol. 2010;2010:327417.

181- Reddy MS, Palcanis KG, Geurs NC. A comparison of manual and controlled-force attachment-level measurements. J Clin Periodontol. 1997;24:920-6.

182- Reinhardt RA, Stoner JA, Golub LM, Lee HM, Nummikoski PV, Sorsa $T$, et al. Association of gingival crevicular fluid biomarkers during periodontal maintenance with subsequent progressive periodontitis. J Periodontol. 2010;81:251-9.

183- Repeke CE, Ferreira SB Jr, Claudino M, Silveira EM, Assis GF, Avila-Campos MJ, et al. Evidences of the cooperative role of the chemokines CCL3, CCL4 and CCL5 and its receptors CCR1+ and CCR5+ in RANKL+ cell migration throughout experimental periodontitis in mice. Bone. 2010;46:1122-30.

184- Repeke CE, Ferreira SB Jr, Vieira AE, Silveira EM, AvilaCampos MJ, Silva JS, et al. Dose-response met-RANTES treatment of experimental periodontitis: a narrow edge between the disease severity attenuation and infection control. PLoS One. 2011;6(7):e22526.

185- Repeke CE, Trombone AP, Ferreira SB Jr, Cardoso CR, Silveira EM, Martins W, et al. Strong and persistent microbial and inflammatory stimuli overcome the genetic predisposition to higher matrix metalloproteinase-1 (MMP-1) expression: a mechanistic explanation for the lack of association of MMP1-1607 singlenucleotide polymorphism genotypes with MMP-1 expression in chronic periodontitis lesions. J Clin Periodontol. 2009;36:726-38. 186- Rescala B, Rosalem W Jr, Teles RP, Fisher RG, Haffajee AD, Socransky SS, et al. Immunologic and microbiologic profiles of chronic and aggressive periodontitis subjects. J Periodontol. 2010;81:1308-16.

187- Restaíno CG, Chaparro A, Valenzuela MA, Kettlun AM, Vernal R, Silva $A$, et al. Stimulatory response of neutrophils from periodontitis patients with periodontal pathogens. Oral Dis. 2007;13:474-81. 188- Rodan GA, Martin TJ. Therapeutic approaches to bone diseases. Science. 2000;289:1508-14. 
189- Rojo-Botello NR, García-Hernández AL, Moreno-Fierros L, Expression of toll-like receptors 2, 4 and 9 is increased in gingival tissue from patients with type 2 diabetes and chronic periodontitis. J Periodontal Res. 2012;47:62-73.

190- Rompikuntal PK, Thay B, Khan MK, Alanko J, Penttinen AM, Asikainen $\mathrm{S}$, et al. Perinuclear localization of internalized outer membrane vesicles carrying active cytolethal distending toxin from Aggregatibacter actinomycetemcomitans. Infect Immun. 2012;80:31-42.

191- Rudensky AY. Regulatory T cells and Foxp3. Immunol Rev. 2011;241:260-8.

192- Saidenberg-Kermanac'h N, Bessis N, Lemeiter D, de Vernejoul MC, Boissier MC, Cohen-Solal M. Interleukin-4 cellular gene therapy and osteoprotegerin decrease inflammation-associated bone resorption in collagen-induced arthritis. J Clin Immunol. 2004; $24: 370-8$.

193- Sakaguchi S, Miyara M, Costantino CM, Hafler DA. FOXP3+ regulatory $T$ cells in the human immune system. Nat Rev Immunol. 2010;10:490-500.

194- Sallusto F, Lanzavecchia A. Heterogeneity of CD4+ memory $T$ cells: functional modules for tailored immunity. Eur J Immunol. 2009;39:2076-82.

195- Sato K, Suematsu A, Okamoto K, Yamaguchi A, Morishita Y, Kadono $Y$, et al. Th17 functions as an osteoclastogenic helper $T$ cell subset that links $T$ cell activation and bone destruction. J Exp Med. 2006;203:2673-82.

196- Sato K, Takayanagi H. Osteoclasts, rheumatoid arthritis, and osteoimmunology. Curr Opin Rheumatol. 2006;18:419-26.

197- Sbardella D, Fasciglione GF, Gioia M, Ciaccio C, Tundo GR, Marini $S$, et al. Human matrix metalloproteinases: an ubiquitarian class of enzymes involved in several pathological processes. Mol Aspects Med. 2012;33:119-208.

198- Schifferle RE, Reddy MS, Zambon JJ, Genco RJ, Levine MJ. Characterization of a polysaccharide antigen from Bacteroides gingivalis. J Immunol. 1989;143:3035-42.

199- Schroder K, Hertzog PJ, Ravasi T, Hume DA. Interferongamma: an overview of signals, mechanisms and functions. J Leukoc Biol. 2004;75:163-89.

200- Sharma A. Virulence mechanisms of Tannerella forsythia. Periodontol 2000. 2010;54:106-16.

201- Shelburne CE, Shelburne PS, Dhople VM, Sweier DG, Giannobile WV, Kinney JS, et al. Serum antibodies to Porphyromonas gingivalis chaperone HtpG predict health in periodontitis susceptible patients. PLoS One. 2008;3:e1984.

202- Shenker BJ, Besack D, McKay T, Pankoski L, Zekavat A, Demuth DR. Induction of cell cycle arrest in lymphocytes by Actinobacillus actinomycetemcomitans cytolethal distending toxin requires three subunits for maximum activity. J Immunol. 2005;174:2228-34.

203- Shevach EM. Mechanisms of foxp3+ T regulatory cell-mediated suppression. Immunity. 2009;30:636-45.

204- Silva N, Dutzan N, Hernandez M, Dezerega A, Rivera O, Aguillon JC, et al. Characterization of progressive periodontal lesions in chronic periodontitis patients: levels of chemokines, cytokines, matrix metalloproteinase-13, periodontal pathogens and inflammatory cells. J Clin Periodontol. 2008;35:206-14.

205- Silva TA, Garlet GP, Fukada SY, Silva JS, Cunha FQ. Chemokines in oral inflammatory diseases: apical periodontitis and periodontal disease. J Dent Res. 2007;86:306-19.

206- Simonet WS, Lacey DL, Dunstan CR, Kelley M, Chang MS, Lüthy $R$, et al. Osteoprotegerin: a novel secreted protein involved in the regulation of bone density. Cell. 1997;89:309-19.

207- Simpson DL, Berthold P, Taichman NS. Killing of human myelomonocytic leukemia and lymphocytic cell lines by Actinobacillus actinomycetemcomitans leukotoxin. Infect Immun. 1988;56:11626.

208- Slots J. Herpesviral-bacterial synergy in the pathogenesis of human periodontitis. Curr Opin Infect Dis. 2007;20:278-83. 209- Slots J. Human viruses in periodontitis. Periodontol 2000. 2010;53:89-110.
210- Slots J, Contreras A. Herpesvirus: a unifying causative factor in periodontitis? Oral Microbiol Immunol. 2000;15:277-80.

211- Socransky S, Haffajee AD. Periodontal microbial ecology. Periodontol 2000. 2005;38:135-87.

212- Socransky SS, Haffajee AD, Goodson JM, Lindhe J. New concepts of destructive periodontal disease. J Clin Periodontol. 1984; $11: 21-32$.

213- Sorsa T, Hernández M, Leppilahti J, Munjal S, Netuschil L, Mäntylä P. Detection of gingival crevicular fluid MMP-8 levels with different laboratory and chair-side methods. Oral Dis. 2010;16:3945.

214- Sorsa T, Mäntylä P, Tervahartiala T, Pussinen PJ, Gamonal J, Hernandez M. MMP activation in diagnostics of periodontitis and systemic inflammation. J Clin Periodontol. 2011;38:817-9.

215- Sorsa T, Tervahartiala T, Leppilahti J, Hernandez M, Gamonal J, Tuomainen AM, et al. Collagenase-2 (MMP-8) as a point-of-care biomarker in periodontitis and cardiovascular diseases. Therapeutic response to non-antimicrobial properties of tetracyclines. Pharmacol Res. 2011;63:108-13.

216- Sorsa T, Tjäderhane L, Konttinen YT, Lauhio A, Salo T, Lee $\mathrm{HM}$, et al. Matrix metalloproteinases: contribution to pathogenesis, diagnosis and treatment of periodontal inflammation. Ann Med. 2006;38:306-21.

217- Sorsa T, Tjäderhane L, Salo T. Matrix metalloproteinases (MMPs) in oral diseases. Oral Dis. 2004;10:311-8.

218- Souza AP, Trevilatto PC, Scarel-Caminaga RM, Brito RB, Line SR. MMP-1 promoter polymorphism: association with chronic periodontitis severity in a Brazilian population. J Clin Periodontol. 2003;30:154-8.

219- Souza AP, Trevilatto PC, Scarel-Caminaga RM, Brito RB Jr, Barros SP, Line SR. Analysis of the MMP-9 (C-1562 T) and TIMP-2 (G-418C) gene promoter polymorphisms in patients with chronic periodontitis. J Clin Periodontol. 2005;32:207-11.

220- Stashenko P, Gonçalves RB, Lipkin B, Ficarelli A, Sasaki H, Campos-Neto $A$. Th1 immune response promotes severe bone resorption caused by Porphyromonas gingivalis. Am J Pathol. 2007; $170: 203-13$.

221- Steinsvoll S, Halstensen TS, Schenck K. Extensive expression of TGF-beta1 in chronically-inflamed periodontal tissue. J Clin Periodontol. 1999;26:366-73.

222- Sugawara $Y$, Uehara A, Fujimoto $Y$, Kusumoto S, Fukase K, Shibata K, et al. Toll-like receptors, NOD1, and NOD2 in oral epithelial cells. J Dent Res. 2006;85:524-9.

223- Takahashi K, Azuma T, Motohira H, Kinane DF, Kitetsu S. The potential role of interleukin-17 in the immunopathology of periodontal disease. J Clin Periodontol. 2005;32:369-74.

224- Takahashi N, Udagawa N, Suda T. A new member of tumor necrosis factor ligand family, ODF/OPGL/TRANCE/RANKL, regulates osteoclast differentiation and function. Biochem Biophys Res Commun. 1999;256:449-55.

225- Takayanagi H. Inflammatory bone destruction and osteoimmunology. J Periodontal Res. 2005;40:287-93.

226- Takayanagi $\mathrm{H}$. Osteoimmunology and the effects of the immune system on bone. Nat Rev Rheumatol. 2009;5:667-76.

227- Takayanagi H, Ogasawara K, Hida S, Chiba T, Murata S, Sato $\mathrm{K}$, et al. T-cell-mediated regulation of osteoclastogenesis by signalling cross-talk between RANKL and IFN-gamma. Nature. 2000;408:600-5.

228- Takeichi O, Haber J, Kawai T, Smith DJ, Moro I, Taubman MA. Cytokine profiles of T-lymphocytes from gingival tissues with pathological pocketing. J Dent Res. 2000;79:1548-55.

229- Tan C, Aziz MK, Lovaas JD, Vistica BP, Shi G, Wawrousek EF, et al. Antigen-specific Th9 cells exhibit uniqueness in their kinetics of cytokine production and short retention at the inflammatory site. J Immunol. 2010;185:6795-801.

230- Taubman MA, Kawai T. Involvement of T-Iymphocytes in periodontal disease and in direct and indirect induction of bone resorption. Crit Rev Oral Biol Med. 2001;12:125-35. 
231- Tay JY, Bay BH, Yeo JF, Harris M, Meghji S, Dheen ST. Identification of RANKL in osteolytic lesions of the facial skeleton. J Dent Res. 2004;83:349-53.

232- Tervahartiala T, Pirilä E, Ceponis A, Maisi P, Salo T, Tuter $G$, et al. The in vivo expression of the collagenolytic matrix metalloproteinases (MMP-2, -8, -13, and -14) and matrilysin (MMP-7) in adult and localized juvenile periodontitis. J Dent Res. 2000;79:1969-77.

233- Tester AM, Cox JH, Connor AR, Starr AE, Dean RA, Puente XS, et al. LPS responsiveness and neutrophil chemotaxis in vivo require PMN MMP-8 activity. PLoS One. 2007;2:e312.

234- Theill LE, Boyle WJ, Penninger JM. RANK-L and RANK: T cells, bone loss, and mammalian evolution. Annu Rev Immunol. 2002; 20:795-823.

235- Tinoco EM, Beldi MI, Loureiro CA, Lana M, Campedelloi F, Tinoco NM, et al. Localized juvenile periodontitis and Actinobacillus actinomycetemcomitans in a Brazilian population. Eur J Oral Sci. 1997;105:9-14.

236- Toh ML, Kawashima M, Hot A, Miossec P, Miossec P. Role of $\mathrm{IL}-17$ in the Th1 systemic defects in rheumatoid arthritis through selective IL-12Rbeta2 inhibition. Ann Rheum Dis. 2010;69:1562-7. 237- Tribble GD, Lamont RJ. Bacterial invasion of epithelial cells and spreading in periodontal tissue. Periodontol 2000. 2010;52:68-83. 238- Trombone AP, Ferreira SB Jr, Raimundo FM, Moura KC, AvilaCampos MJ, Silva JS, et al. Experimental periodontitis in mice selected for maximal or minimal inflammatory reactions: increased inflammatory immune responsiveness drives increased alveolar bone loss without enhancing the control of periodontal infection. J Periodontal Res. 2009;44:443-51.

239- Udagawa N, Horwood NJ, Elliott J, Mackay A, Owens J, Okamura $\mathrm{H}$, et al. Interleukin-18 (interferon-gamma-inducing factor) is produced by osteoblasts and acts via granulocyte/ macrophage colony-stimulating factor and not via interferon-gamma to inhibit osteoclast formation. J Exp Med. 1997;185:1005-12. 240- Uehara A, Takada H. Functional TLRs and NODs in human gingival fibroblasts. J Dent Res. 2007;86:249-54.

241- Ustun K, Alptekin NO, Hakki SS, Hakki EE. Investigation of matrix metalloproteinase-1 - $16071 \mathrm{G} / 2 \mathrm{G}$ polymorphism in a Turkish population with periodontitis. J Clin Periodontol. 2008;35:1013-9. 242- Van Lint P, Wielockx B, Puimège $L$, Noël A, López-Otin C, Libert C. Resistance of collagenase-2 (matrix metalloproteinase8)-deficient mice to TNF-induced lethal hepatitis. J Immunol. 2005; 175:7642-9.

243- Van Winkelhoff AJ, Appelmelk BJ, Kippuw N, de Graaff J. K antigens in Porphyromonas gingivalis are associated with virulence. Oral Microbiol Immunol. 1993;8:259-65.

244- Verdier J, Begue B, Cerf-Bensussan N, Ruemmele FM. Compartmentalized expression of Th1 and Th17 cytokines in pediatric inflammatory bowel diseases. Inflamm Bowel Dis. 2012;18:1260-6.

245- Vernal R, Chaparro A, Graumann R, Puente J, Valenzuela MA, Gamonal J. Levels of cytokine receptor activator of nuclear factor kappaB ligand in gingival crevicular fluid in untreated chronic periodontitis patients. J Periodontol. 2004;75:1586-91.

246- Vernal R, Dezerega A, Dutzan N, Chaparro A, León R, Chandía $S$, et al. RANKL in human periapical granuloma: possible involvement in periapical bone destruction. Oral Dis. 2006;12:283-9.

247- Vernal R, Dutzan N, Chaparro A, Puente J, Antonieta Valenzuela M, Gamonal J. Levels of interleukin-17 in gingival crevicular fluid and in supernatants of cellular cultures of gingival tissue from patients with chronic periodontitis. J Clin Periodontol. 2005;32:383-9.

248- Vernal R, Dutzan N, Hernández M, Chandía S, Puente J, León $R$, et al. High expression levels of receptor activator of nuclear factor-kappa $B$ ligand associated with human chronic periodontitis are mainly secreted by CD4+ T lymphocytes. J Periodontol. 2006; 77:1772-80.
249- Vernal R, León R, Silva A, van Winkelhoff AJ, Garcia-Sanz JA, Sanz M. Differential cytokine expression by human dendritic cells in response to different Porphyromonas gingivalis capsular serotypes. J Clin Periodontol. 2009;36:823-9.

250- Walsh MC, Choi Y. Biology of the TRANCE axis. Cytokine Growth Factor Rev. 2003;14:251-63.

251- Walsh MC, Kim N, Kadono Y, Rho J, Lee SY, Lorenzo J, et al. Osteoimmunology: interplay between the immune system and bone metabolism. Annu Rev Immunol. 2006;24:33-63.

252- Wan YY. Multi-tasking of helper T cells. Immunology. 2010;130:166-71.

253- Wang Y, Rosen H, Madtes DK, Shao B, Martin TR, Heinecke JW, et al. Myeloperoxidase inactivates TIMP-1 by oxidizing its $\mathrm{N}$-terminal cysteine residue: an oxidative mechanism for regulating proteolysis during inflammation. J Biol Chem. 2007;282:31826-34.

254- Watanabe K, Iizuka T, Adeleke A, Pham L, Shlimon AE, Yasin $M$, et al. Involvement of toll-like receptor 4 in alveolar bone loss and glucosehomeostasis in experimental periodontitis. J Periodontal Res. 2011;46:21-30.

255- Weaver CT, Harrington LE, Mangan PR, Gavrieli M, Murphy KM. Th17: an effector CD4 T cell lineage with regulatory $T$ cell ties. Immunity. 2006;24:677-88.

256- Ximenez-Fyvie LA, Almaguer-Flores A, Jacobo-Soto V, Lara-Cordoba M, Moreno-Borjas JY, Alcantara-Maruri E. Subgingival microbiota of periodontally untreated Mexican subjects with generalized aggressive periodontitis. J Clin Periodontol. 2006;33:869-77.

257- Xing J, Wu Y, Ni B. Th9: a new player in asthma pathogenesis? J Asthma. 2011;48:115-25.

258- Yamamoto T, Kita M, Oseko F, Nakamura T, Imanishi J, Kanamura N. Cytokine production in human periodontal ligament cells stimulated with Porphyromonas gingivalis. J Periodontal Res. 2006;41:554-9.

259- Yamazaki S, Bonito AJ, Spisek R, Dhodapkar M, Inaba K, Steinman RM. Dendritic cells are specialized accessory cells along with TGF- for the differentiation of Foxp3 + CD4+ regulatory T cells from peripheral Foxp3 precursors. Blood. 2007;110:4293-302.

260- Yasuda H, Shima N, Nakagawa N, Yamaguchi K, Kinosaki M, Mochizuki S, et al. Osteoclast differentiation factor is a ligand for osteoprotegerin/osteoclastogenesis-inhibitory factor and is identical to TRANCE/RANKL. Proc Natl Acad Sci U S A. 1998;31:95:3597-602. 261- Yilmaz O. The chronicles of Porphyromonas gingivalis: the microbium, the human oral epithelium and their interplay. Microbiology. 2008;154:2897-903.

262- Yu JJ, Ruddy MJ, Wong GC, Sfintescu C, Baker PJ, Smith JB, et al. An essential role for IL-17 in preventing pathogen-initiated bone destruction: recruitment of neutrophils to inflamed bone requires IL-17 receptor-dependent signals. Blood. 2007;109:3794-802.

263- Zappa U, Reinking-Zappa M, Graf H, Espeland M. Cell populations and episodic periodontal attachment loss in humans. ] Clin Periodontol. 1991;18:508-15.

264- Ziolkowska M, Koc A, Luszczykiewicz G, Ksiezopolska-Pietrzak K, Klimczak E, Chwalinska-Sadowska $H$, et al. High levels of IL17 in rheumatoid arthritis patients: IL-15 triggers in vitro IL-17 production via cyclosporin A-sensitive mechanism. J Immunol. 2000;164:2832-8.

265- Zhou Q, Amar S. Identification of signaling pathways in macrophage exposed to Porphyromona gingivalis or to its purified cell wall components. J Immunol. 2007;179:7777-90.

266- Zhu J, Paul WE. Heterogeneity and plasticity of T helper cells. Cell Res. 2010;20:4-12.

267- Zhu J, Yamane H, Paul WE. Differentiation of effector CD4 T cell populations. Annu Rev Immunol. 2010;28:445-89. 